OPEN ACCESS

Edited by:

Mónica Sánchez-Román, VU University Amsterdam,

Netherlands

Reviewed by:

Eloi Camprubí Casas,

Utrecht University, Netherlands

Ulrike Kappler,

The University of Queensland,

Australia

Xiaoguo Yu,

State Oceanic Administration, China

*Correspondence:

Daniel Carrizo

dcarrizo@cab.inta-csic.es

Specialty section:

This article was submitted to

Microbiological Chemistry

and Geomicrobiology,

a section of the journal

Frontiers in Microbiology

Received: 21 September 2018

Accepted: 31 December 2018

Published: 15 January 2019

Citation:

Sanchez-Garcia L,

Fernandez-Martinez MA,

García-Villadangos M, Blanco Y, Cady SL, Hinman N, Bowden ME,

Pointing SB, Lee KC,

Warren-Rhodes K, Lacap-Bugler $D$,

Cabrol NA, Parro $V$ and Carrizo $D$

(2019) Microbial Biomarker Transition

in High-Altitude Sinter Mounds From

El Tatio (Chile) Through Different

Stages of Hydrothermal Activity.

Front. Microbiol. 9:3350.

doi: 10.3389/fmicb.2018.03350

\section{Microbial Biomarker Transition in High-Altitude Sinter Mounds From El Tatio (Chile) Through Different Stages of Hydrothermal Activity}

\author{
Laura Sanchez-Garcia', Miguel Angel Fernandez-Martinez', \\ Miriam García-Villadangos ${ }^{1}$, Yolanda Blanco', Sherry L. Cady², Nancy Hinman ${ }^{3}$, \\ Mark E. Bowden', Stephen B. Pointing ${ }^{4}$, Kevin C. Lee ${ }^{5}$, Kimberly Warren-Rhodes ${ }^{6,7}$, \\ Donnabella Lacap-Bugler ${ }^{5}$, Nathalie A. Cabrol',7, Victor Parro ${ }^{1}$ and Daniel Carrizo ${ }^{1 *}$
}

\footnotetext{
${ }^{1}$ Centro de Astrobiología (CSIC-INTA), Madrid, Spain, ${ }^{2}$ Environmental Molecular Sciences Laboratory, Pacific Northwest National Laboratory, Richland, WA, United States, ${ }^{3}$ Department of Geosciences, University of Montana, Missoula, MT, United States, ${ }^{4}$ Yale-NUS College, National University of Singapore, Singapore, Singapore, ${ }^{5}$ School of Science, Auckland University of Technology, Auckland, New Zealand, ${ }^{6}$ SETI Institute, Mountain View, CA, United States, ${ }^{7}$ NASA Ames Research Center, Moffett Field, CA, United States
}

Geothermal springs support microbial communities at elevated temperatures in an ecosystem with high preservation potential that makes them interesting analogs for early evolution of the biogeosphere. The El Tatio geysers field in the Atacama Desert has astrobiological relevance due to the unique occurrence of geothermal features with steep hydrothermal gradients in an otherwise high altitude, hyper-arid environment. We present here results of our multidisciplinary field and molecular study of biogeochemical evidence for habitability and preservation in silica sinter at El Tatio. We sampled three morphologically similar geyser mounds characterized by differences in water activity (i.e., episodic liquid water, steam, and inactive geyser lacking hydrothermal activity). Multiple approaches were employed to determine (past and present) biological signatures and dominant metabolism. Lipid biomarkers indicated relative abundance of thermophiles (dicarboxylic acids) and sulfate reducing bacteria (branched carboxylic acids) in the sinter collected from the liquid water mound; photosynthetic microorganisms such as cyanobacteria (alkanes and isoprenoids) in the steam sinter mound; and archaea (squalane and crocetane) as well as purple sulfur bacteria (cyclopropyl acids) in the dry sinter from the inactive geyser. The three sinter structures preserved biosignatures representative of primary (thermophilic) and secondary (including endoliths and environmental contaminants) microbial communities. Sequencing of environmental $16 S$ rRNA genes and immuno-assays generally corroborated the lipid-based microbial identification. The multiplex immunoassays and the compound-specific isotopic analysis of carboxylic acids, alkanols, and alkanes indicated that the principal microbial pathway for carbon fixation in the three sinter mounds was through the Calvin cycle, with a relative larger contribution of the reductive acetyl-CoA pathway in the dry system. Other inferred metabolic traits varied from the liquid mound (iron and sulfur chemistry), to the steam mound (nitrogen cycle), to the dry mound (perchlorate reduction). The combined 
results revealed different stages of colonization that reflect differences in the lifetime of the mounds, where primary communities dominated the biosignatures preserved in sinters from the still active geysers (liquid and steam mounds), in contrast to the surviving metabolisms and microbial communities at the end of lifetime of the inactive geothermal mound.

Keywords: lipid biomarkers, microbial transition, hydrothermal activity, sinter mounds, high altitude geyser field, biogeochemical reconstruction

\section{INTRODUCTION}

Geothermal springs are natural environments of scientific interest because of their significance in the early evolution of the biogeosphere (Walter and Des Marais, 1993; Konhauser et al., 2003; Cady et al., 2018). Despite their apparent in hospitability, terrestrial geothermal springs are recognized habitats for microbial life on Earth (Brock, 1978). Indeed, they are considered some of the candidate sites where life began (Van Kranendonk et al., 2017), in contrast to the classical sub-marine hydrothermal-vents theory including the alkaline hydrothermal vent model (Russell, 2018). Though surficial hydrothermal vents are characterized by steep geothermal gradients and a perpetual supply of nutrients, geothermal springs also provide an environment in which intermittent wetting and drying of hydrothermal precipitates occurs due to the stochastic nature of surface geothermal activity (Damer and Deamer, 2015). Alternating wet and dry periods of hydrothermal activity promotes the interaction of simple molecular building blocks to form complex molecules (Deamer and Georgiou, 2015). Although not consensus exists on whether wet-dry cycling played a role during abiogenesis (Russell, 2018), the possibility of a landbased origin of life strengthens the relevance of such settings for astrobiological exploration (Van Kranendonk et al., 2017).

Geothermal springs and geysers are manifestations of volcanic or impact activity on a wet rocky planet (Sillitoe, 2015). The interaction of groundwater with solidified but still-hot country rock at shallow depths provides a variety of potential niches for heat-loving microbes. In such geothermal systems, groundwater percolates through fractures in igneous rock deep underground, where heat from the nearby magma chamber heats the pressurized fluid to a temperature above its boiling point at surface pressure. Rising superheated fluid emerges at surface effluents associated with hot spring pools and geysers as a column of hot water and steam that erupts episodically as steam and fluid separate as they rise to surface. Fumaroles are characterized exclusively by steam-driven hydrological activity. Regardless of the surface expression of subsurface hydrothermal activity, the environmental conditions of such settings are extreme. Water and steam temperatures are typically several tens of degrees (that extend to the local temperature of boiling) above mean air temperatures, and the $\mathrm{pH}$ of the fluid can range from acidic to alkaline. When the elemental content of hydrothermal fluids is high (i.e., high concentration of dissolved silica, calcium, or carbonates), sinter precipitation occurs. The metals contents $(\mathrm{Fe}, \mathrm{Mn}$, and $\mathrm{Mg}$ ), including toxic metals (e.g., $\mathrm{Sb}, \mathrm{B}$, or $\mathrm{As}$ ) of hydrothermal systems can be abundant. In these extreme environments, only the microorganisms particularly resistant and adapted to adverse conditions are able to thrive. Their distribution and community structures appears to be mostly determined by factors such as temperature, $\mathrm{pH}$, or the content of hydrogen sulfide (e.g., Purcell et al., 2007), as demonstrated by diverse studies on geothermal springs from Yellowstone National Park (Cady and Farmer, 1996), Thailand (Purcell et al., 2007), California and Nevada (Zhang et al., 2007), or New Zealand (e.g., Pantcost et al., 2005; Kaur et al., 2015). Temperature is limiting for certain groups such as phototrophic bacteria (e.g., cyanobacteria, green sulfur and non-sulfur bacteria), as their growth is seriously hampered at temperatures greater than $73^{\circ} \mathrm{C}$ (Ward et al., 1998; Miller and Castenholz, 2000). Conversely, chemolithoautotrophs such as Aquificales are well adapted to thrive in such high temperatures (Reysenbach et al., 1994; Kato et al., 2004). Moreover, hydrogen sulfide is a well-known inhibiting factor of cyanobacteria (Castenholz, 1973; Giovannoni et al., 1987), while it enhances or necessitates the growth of phototrophic sulfur bacteria (Madigan, 1986; van der Meer et al., 2000) or certain species of Aquificales (Skirnisdottir et al., 2000; Nakagawa and Fukui, 2003; Kato et al., 2004). Taken together, geothermal springs are ideal settings for investigating habitability and adaptability of extremophiles in relation to various environmental conditions (Lacap et al., 2007; Purcell et al., 2007; Lau et al., 2008).

Geothermal springs continuously release mineral-rich fluids that precipitate sinters (typically opaline silica, bicarbonate, or iron oxide) with morphologically and microstructurally distinct attributes and they preserve evidence of the microbial communities that thrived at that location when the sinter precipitated (i.e., primary communities) (Cady and Farmer, 1996; Renaut et al., 1998; Farmer and Des Marais, 1999; Fouke et al., 2000; Parenteau and Cady, 2010; Campbell et al., 2015). Once hydrothermal fluids vent at the surface, the dynamic combination of evaporation and cooling of thermal waters precipitates sinter deposits via heterogeneous and homogeneous nucleation and polymerization (Fournier and Rowe, 1977). Sinter precipitates begin to dry out along the hydrothermal terraces or cones as the distance to the spring vent increases and the hot fluids cool and evaporate. Sinter accretion typically encrusts, emtombs, and replaces these biological remnants (Cady and Farmer, 1996; Renaut et al., 1998; Campbell et al., 2015). The rapid, kinetically driven precipitation of mineraloids and minerals preserves organic biomarkers over geological time as distinct hydrothermal lithofacies (Schopf and Packer, 1987; Campbell et al., 2015; 
Westall et al., 2015). In addition, new microbial populations colonize (secondary communities) when the environmental conditions change along the hydrothermal activity lifetime. As a consequence, a variety of microbial communities thrive in distinct biofacies of geothermal springs. Hot spring deposits and the preservation of their biosignatures provide insights into the evolution of early life (Cady et al., 2018) and can inform astrobiological search strategies (Walter and Des Marais, 1993; Farmer and Des Marais, 1999).

The preservation of organic compounds in sinter deposits has been studied in geothermal springs of the major geyser fields worldwide, including Yellowstone National Park (e.g., Jahnke et al., 2001; Pepe-Ranney et al., 2012), Iceland (e.g., Konhauser et al., 2001; Tobler and Benning, 2011); Kamchatka (Goin and Cady, 2009), Tibet (Lau et al., 2008), or New Zealand (e.g., Jones et al., 2001; Pantcost et al., 2005; Kaur et al., 2015). In comparison to most other hydrothermal settings, our understanding of organic preservation in sinter deposits at $E l$ Tatio (Chile), the third largest geyser field in the world and the largest in the southern hemisphere, is limited. Located within the Andes Mountains, El Tatio is one of the highest hydrothermal systems $(4,320$ mamsl), which subjects it to unique conditions such as intense UV-A and UV-B radiation, an unusually low water-boiling point $\left(86^{\circ} \mathrm{C}\right)$, and severe climatic changes including large daily thermal oscillation and high atmospheric dryness (Fernandez-Turiel et al., 2005). These and other specific limiting factors for life at $\mathrm{El} \mathrm{Tatio,} \mathrm{including} \mathrm{a} \mathrm{toxic} \mathrm{chemistry} \mathrm{of} \mathrm{the}$ geothermal-springs water (B, As, or $\mathrm{Sb})$, make the geothermal field an extreme environment of interest for understanding the development and persistence of life under severe conditions, as well as a terrestrial model of a Martian environment. This model includes, apart from the extreme aridity, high solar radiation, salinity and oxidant conditions during the last 1015 millions of years characteristic of the Atacama Desert environments (e.g., Navarro-González et al., 2003), presence of volcanic and hydrothermal activity such as that in the ancient Mars. El Tatio serves as a natural laboratory for the study of the biogeochemical processes involved in the deposition and alteration of siliceous sinter and the potential for preserving microbial biosignatures. Yet, the few existing microbiological studies on El Tatio are focused on petrographic and mineralogical examinations (Fernandez-Turiel et al., 2005), thermal imaging (Dunckel et al., 2009), electron microscopy and UV-spectroscopy (Phoenix et al., 2006), or optical/scanning electron microscopy and molecular (DNA) methods (Barbieri et al., 2014). To the best of our knowledge, no studies have integrated microbiological and biogeochemical approaches for exploring the preservation of microbial biosignatures on sinter deposits from geothermal springs at El Tatio.

In this work, we investigated the presence and potential to preserve molecular biomarkers in sinter deposits from three geothermal-spring mounds at $E l$ Tatio. The springs are within $75 \mathrm{~m}$ of each other in the Upper Basin of El Tatio. Thermal features in the basin tap a $\sim 200-220 \mathrm{C}$ hydrothermal reservoir at $<250 \mathrm{~m}$ in the subsurface (Giggenbach, 1978; Muñoz-Saez et al., 2018). As in geyser basins worldwide, individual thermal features transition between actively emitting water or steam, and inactivity. This episodic nature of thermal activity is dictated by the subsurface fracture system, which is maintained through earthquake activity (Fournier, 1989). Consequently, any study of geysers and hot springs represents a snapshot in time. We use this snapshot to document and compare the microbial community and its associated biogeochemistry of each feature. The nature of the hydrothermal activity (or lack thereof) of these three mounds represented different stages in the lifetime of such features and ranged from abundant water discharged during geyser activity to steam to complete dryness. Because the system is dynamic, there is the potential for population shifts in the microbial communities as environmental conditions change (Smith et al., 2003; Lynne, 2015). This snapshot, therefore, combines the signatures of the original microbial community with those of any opportunistic communities that might arise as conditions change. We use visual and petrographic observations to control for such changes. We combined the use of lipid biomarkers and organic isotopic composition with immunological (sandwich microarray immunoassay) and genomic (DNA sequencing) techniques to investigate the microbial community and functionality in the three sinter mounds. Characterization of the morphological features and geochemistry of the sinter provided an ecological framework for interpreting the molecular and isotopic results. Compound-specific isotopic analysis of lipid biomarkers was employed to obtain information about different carbon cycling pathways; DNA sequencing was used to characterize the phylogenetic groups; and antibody microarrays were interrogated to demonstrate the presence of certain microbial strains and proteins involved in some metabolic and/or environmental traits. Mineralogy was identified with X-ray diffraction, and lithofacies traits preserved in the sinters were revealed by optical and electron microscopy. This multi-analytical (molecular, isotopic, genomic, mineralogical, geochemical, and paleobiological) approach was successful in explaining the influence of the degree of hydrothermal activity on the biomarkers record (i.e., from past and present) in sinter deposits from high altitude mounds at El Tatio. This is the first multidisciplinary molecular study of the biogeochemical evidence preserved in the sinter formations at El Tatio, which reveals more about the habitability, adaptability, and preservation of biosignatures in this type of Mars analog environment.

\section{MATERIALS AND METHODS}

\section{Field Settings}

El Tatio geysers field $\left(22^{\circ} 20^{\prime} \mathrm{S}\right.$ and $\left.68^{\circ} \mathrm{W}\right)$ is located in the Andean highlands (i.e., Altiplano) near the Atacama Desert, northern Chile (Figure 1). This hydrothermal area consists of three distinct basins: Upper, Middle, and Lower Geyser Basins. The Middle Basin is composed of pools, fountain-type geysers, and the runoff streams from geothermal springs and pools (Glennon and Pfaff, 2003). The El Tatio geysers field, located along the Salado River Valley, contains more than 80 active geysers, fumaroles, geothermal springs, and mud volcanoes and is surrounded by extensive sinter terraces and aprons that spread over an area of approximately $10 \mathrm{~km}^{2}$. El Tatio is in 


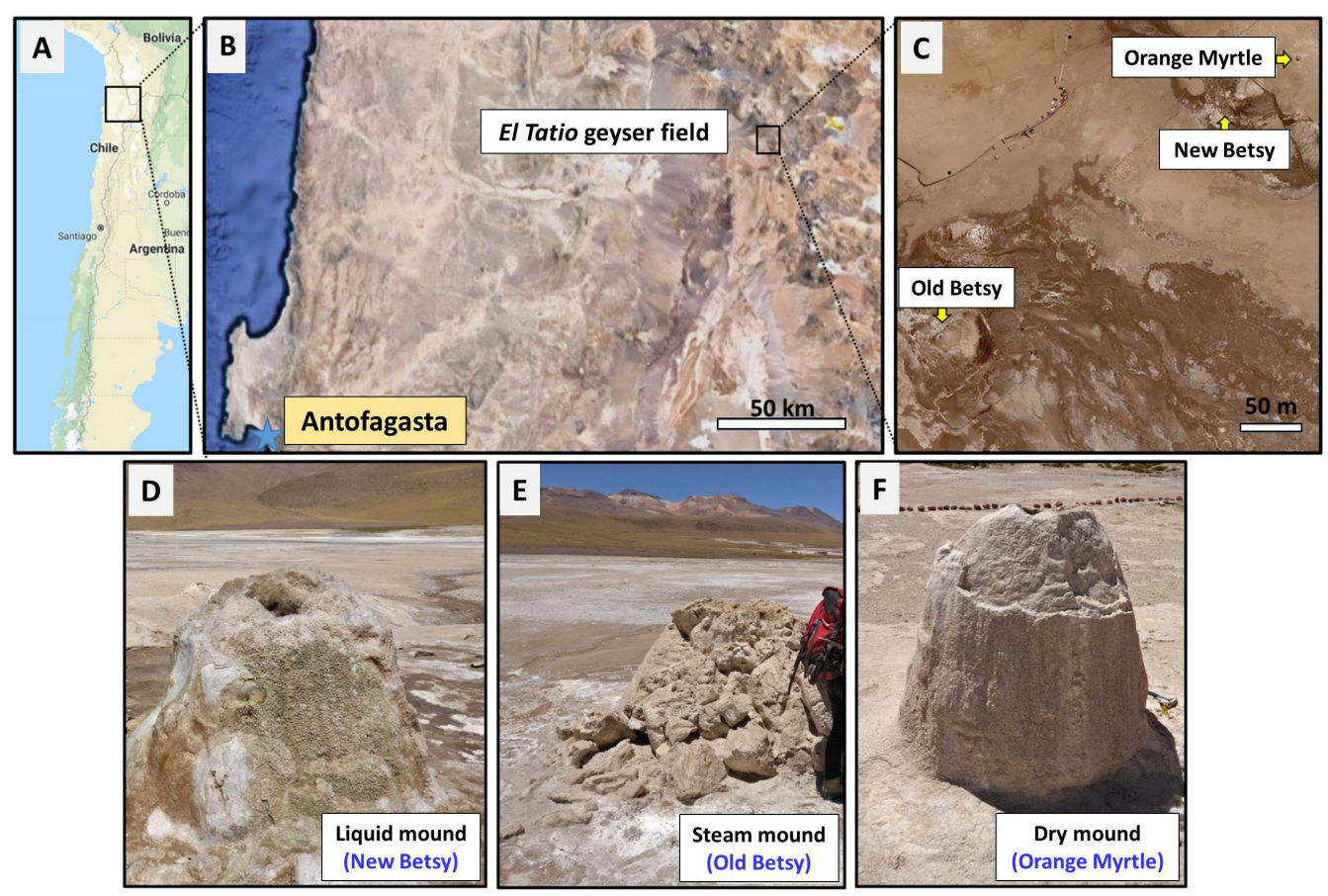

FIGURE 1 | Site of study and sampling. Map of northern Chile (A), showing the location of the El Tatio geysers field (B), including the three geysers studied here (New Betsy, NB; Old Betsy, OB; and Orange Myrtle, OM) (C). Both pictures in B,C are satellite images from Google Maps. The general appearance of the three sinter mounds (liquid NB, steam OB, and dry OM) is shown in $\mathbf{D}-\mathbf{F}$, respectively.

a geological region composed of Jurassic marine sediments, Jurassic-Cretaceous andesites, Cretaceous sediments, Miocene ignimbrites and andesites, and Plio-Holocene lavas, domes, dacitic and rhyolitic ignimbrites (Lahsen and Trujillo, 1976). This geological sequence is overlain by glacial and alluvial deposits, which are locally covered by silica sinter deposits (Fernandez-Turiel et al., 2005). The extensive siliceous sinter formations at $\mathrm{El} \mathrm{Tatio}$ are the result of silica precipitation from near-neutral thermal waters with a $\mathrm{SiO}_{2}$ concentration of 147$285 \mathrm{mg} / \mathrm{l}$ (Nicolau et al., 2014). Sedimentary microtextures in the sinter deposits suggested that the microbial community at El Tatio is moderately diverse, with a variety of extreme biological communities of thermophilic bacteria (Chloroflexuslike), cyanobacteria, and diatoms (Fernandez-Turiel et al., 2005).

\section{Sample Collection}

Samples were collected from El Tatio geysers field (Figure 1) in October 2016, during a NASA Astrobiology Institute NAICAN 7 project ("Changing Planetary Environments and the Fingerprints of Life") sampling campaign. Sinter samples were collected from three sinter mounds that appeared similar based on their size and the shape of the mounds, though differed in terms of their hydrological environment. As shown in Figure 1, the active-geyser mound known as New Betsy (NB) had abundant liquid water $\left(\sim 84^{\circ} \mathrm{C}\right)$ that flowed from the mound, episodically covering the mound surface; the morphologically similar mound known as Old Betsy (OB) had a supply of steam $\left(\sim 75^{\circ} \mathrm{C}\right)$ that enveloped various surfaces of the mound where samples were collected; and the inactive mound known as Orange Myrtle (OM) lacked both hydrothermal water and steam. For convenience, and to emphasize the distinct differences in the hydrological regime, we refer to the collected sinter samples as belonging to the liquid, steam, and dry mounds (Figures 1d-f). About $100 \mathrm{~g}$ of sinter sample were collected from equivalent sampling spots (i.e., half way down) from the three sinter mounds with a geological hammer and broken samples were gathered with a solvent-cleaned (DCM and $\mathrm{MeOH}$ ) stainless-steel spatula. They were wrapped in aluminum foil and transported in solvent-clean containers for biogeochemical analysis at the CAB (Centro de Astrobiología). A sample of hydrothermal fluid was also collected from New Betsy for geochemical analysis. Physical splits of the samples were distributed to collaborators at different locations in the United States.

\section{Lithofacies and Scanning Electron Microscopy}

The lithofacies of the sinter samples were described using terminology consistent with the lithofacies model for silica sinters provided by Walter (1976), based on the gross morphological features of laminated sinters. The sinter samples were air dried during transport and analyzed as bulk fragments to identify the distribution of morphological features consistent with silicified biological remnants in the context of their biofabrics. The biofabrics were identified with conventional stereoscopic and a scanning electron microscopic methods on fractured and sawn surfaces oriented perpendicular to the lamination. The use of the 
biological holder of a Phenom Pro scanning electron microscope (SEM) eliminated the need for carbon coating, though smaller fractured fragments of sinter were often carbon coated to reduce artifacts in the SEM images that were created by regions of higher porosity.

\section{Mineralogical and Geochemical Analyses}

$\mathrm{X}$-ray diffraction analysis was performed on different splits of the sinter samples at CAB and PNNL (Pacific Northwest National Laboratory). At $\mathrm{CAB}$, the three sinter samples were analyzed using a Bruker X-Ray diffractometer (Eco-D8 advance, XRD) to determine the silica phase and associated mineralogy. Dry samples of the three sinter mounds were ground, mounted on a PMMA specimen holder and scanned between $5^{\circ}$ to $60^{\circ} 2 \theta$, with a scanning step size of $1 \mathrm{~s}$ and $0.05^{\circ}$, operated at $40 \mathrm{kV}$

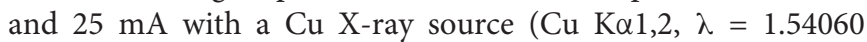
$\AA$ ). At PNNL, X-ray diffraction data were collected with the use of a Panalytical MPD Bragg-Brentano goniometer fitted with a $\mathrm{Cu}$ X-ray source operated at $45 \mathrm{kV}$ and $40 \mathrm{~mA}$, fitted with variable divergence slits (10 $\mathrm{mm}$ illuminated length) and a postdiffraction monochromator. The powders were loaded into the cavity of a zero-background holder and patterns were collected between 5 and $100^{\circ} 2 \theta$ with 4 s counts at $0.04^{\circ}$ intervals.

Inorganic anions and organic acids of low molecular weight were determined by ion chromatography in the water-extractable phase of the three sinter samples (liquid, steam, and dry), or in the water sample from New Betsy, according to previous descriptions (Parro et al., 2011a; Sánchez-García et al., 2018). Briefly, 2 g of the sinter samples and $1 \mathrm{ml}$ of the water sample were sonicated ( $3 \mathrm{~min} \times 1 \mathrm{~min}$ cycles) and diluted in $10 \mathrm{~mL}$ of deionized water; then filtered (0.22 $\mu \mathrm{m}$ GFF), and analyzed in a Metrohm 861 Advanced compact ion chromatographer (Metrohm AG, Herisau, Switzerland), using 3.6 mM sodium carbonate $\left(\mathrm{NaCO}_{3}\right)$ as eluent.

Stable isotopes of organic carbon $\left(\delta^{13} \mathrm{C}\right)$ and total nitrogen $\left(\delta^{15} \mathrm{~N}\right)$ were measured on the bulk sinter samples with isotoperatio mass spectrometry (IRMS), following USGS methods (Révész et al., 2012). Briefly, sinter samples (2 g) were homogenized by grinding with a corundum mortar and pestle. Subsequently, $\mathrm{HCl}$ was added to the samples to remove carbonates, equilibrated for $24 \mathrm{~h}$, and adjusted to neutral $\mathrm{pH}$ with ultrapure water. The residue was then dried in an oven $\left(50^{\circ} \mathrm{C}\right)$ for $72 \mathrm{~h}$ or until a constant weight was achieved and analyzed in the IRMS (MAT 253, Thermo Fisher Scientific). $\delta^{13} \mathrm{C}$ and $\delta^{15} \mathrm{~N}$ values were reported in the standard per mil notation using three certified standards (USGS41, IAEA-600, and USGS40) with an analytical precision of $0.1 \%$. The content of total organic carbon (TOC \%) and total nitrogen (TN \%) was measured with an elemental analyzer (HT Flash, Thermo Fisher Scientific), during the stable isotope measurements.

\section{Geolipids Extraction, Fractionation, and Analysis}

About $50 \mathrm{~g}$ of the sinter samples were Soxhlet extracted $(24 \mathrm{~h})$ with a mixture (ca. $250 \mathrm{ml}$ ) of dichloromethane/methanol (DCM/MeOH, 3:1, v/v), after addition of internal standards (tetracosane- $\mathrm{D}_{50}$, myristic acid- $\mathrm{D}_{27}, 2$-hexadecanol). The total lipid extracts were concentrated to ca. $2 \mathrm{ml}$ by rotary evaporation and elemental sulfur removed overnight with activated copper. The clean extract was separated into two fractions of different polarity (neutral and acidic) using Bond-elute (bond phase $\mathrm{NH}_{2}$, $500 \mathrm{mg}, 40 \mu \mathrm{m}$ particle size) chromatography columns. A neutral lipid fraction was obtained by eluting with $15 \mathrm{ml} \mathrm{DCM} / 2$ propanol $(2: 1, \mathrm{v} / \mathrm{v})$ and an acidic fraction with $15 \mathrm{ml}$ of acetic acid (2\%) in diethyl ether. Further separation of the neutral fraction into non-polar and polar sub-fractions was done with $0.5 \mathrm{~g}$ of alumina (activated, neutral, $0.05-0.15 \mathrm{~mm}$ particle size) in a precombusted Pasteur pipet. The non-polar fraction was obtained by eluting $4.5 \mathrm{ml}$ of hexane/DCM $(9: 1, \mathrm{v} / \mathrm{v})$ and the polar fraction with $3 \mathrm{ml}$ of $\mathrm{DCM} / \mathrm{methanol}(1: 1, \mathrm{v} / \mathrm{v})$. The acidic fraction was derivatized with $\mathrm{BF}_{3}$ in methanol and the polar fraction with N,O-bis (trimethylsilyl) trifluoroacetamide (BSTFA).

The three lipid fractions (non-polar, acid, and polar fraction) were analyzed with gas chromatography mass spectrometry using a 6850 GC system coupled to a $5975 \mathrm{VL}$ MSD with a triple axis detector (Agilent Technologies) operating in conditions previously described elsewhere (Sánchez-García et al., 2018). For the non-polar fraction, the oven temperature was programmed from 50 to $130^{\circ} \mathrm{C}$ at $20^{\circ} \mathrm{C} \mathrm{min}^{-1}$ and then to $300^{\circ} \mathrm{C}$ at $6^{\circ} \mathrm{C}$ $\mathrm{min}^{-1}$ (held $20 \mathrm{~min}$ ); for the acidic fraction, from 70 to $130^{\circ} \mathrm{C}$

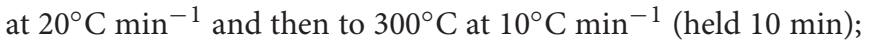
and, for the polar fraction, the oven temperature program was the same as that for the acidic fraction, except that the oven was held for $15 \mathrm{~min}$ at $300^{\circ} \mathrm{C}$. The injector temperature was $290^{\circ} \mathrm{C}$, the transfer line was at $300^{\circ} \mathrm{C}$, and the MS source at $240^{\circ} \mathrm{C}$. Compounds identification was based on the comparison of mass spectra with reference materials, and their quantification on the use of external calibration curves of $n$-alkanes $\left(\mathrm{C}_{10}\right.$ to $\mathrm{C}_{40}$ ), fatty acids methyl esters (FAME; $\mathrm{C}_{8}$ to $\left.\mathrm{C}_{24}\right), n$-alkanols $\left(\mathrm{C}_{10}\right.$, $\mathrm{C}_{14}, \mathrm{C}_{18}$, and $\mathrm{C}_{20}$ ), and branched isoprenoids (2,6,10-trimethyldocosane, crocetane, pristane, phytane, squalane, and squalene). All chemicals and standards were supplied by Sigma Aldrich. The recovery of the internal standards averaged $69 \pm 18 \%$.

\section{Compound Specific Isotope Analysis}

Carbon isotopic compositions of individual lipid compounds ( $n$-alkanes, carboxylic acids as FAMEs, and n-alkanols) were performed coupling the gas chromatograph (Trace GC 1310 ultra) to the isotope-ratio mass spectrometry system (MAT 253 IRMS, Thermo Fisher Scientific). The conditions for the GC analysis were identical to those used for the polar fraction analysis, whereas the conditions for the IRMS analysis were as follows: electron ionization $100 \mathrm{eV}$, Faraday cup collectors $\mathrm{m} / z$ 44,45 , and 46 , and a temperature of the $\mathrm{CuO} / \mathrm{NiO}$ combustion interface of $1000^{\circ} \mathrm{C}$. The samples were injected in splitless mode, with inlet temperature of $250^{\circ} \mathrm{C}$, and helium as a carrier gas at constant flow of $1.1 \mathrm{ml} \mathrm{min}{ }^{-1}$. The isotopic values of the individual lipids separated by GC were calculated using $\mathrm{CO}_{2}$ spikes of known isotopic composition, introduced directly into the MS source, three times at the beginning and end of every run. Reference mixtures (Indiana University, United States) of known isotopic composition of $n$-alkanes (A6) and FAMEs (F8) were run after every four samples to check accuracy of the 
isotopic ratio determined by the GC-IRMS. The $\delta^{13} \mathrm{C}$ data for individual carboxylic acids (i.e., n-carboxylic acids, iso/anteiso and unsaturated) were calculated from the obtained FAME values, by correcting them for the one carbon atom added in the methanolysis (Abrajano et al., 1994).

\section{DNA Extraction, PCR Amplification, and DNA Sequencing}

Genomic DNA was extracted from the three sinter samples, using the CTAB genomic DNA extraction method (WarrenRhodes et al., 2018). Bacterial 16S rDNA V3-V4 gene region from all DNA extracts was then PCR amplified, using the primer pairs 341-F/805-R (Herlemann et al., 2011). Archaeal $16 \mathrm{~S}$ rDNA V3-V4 region was PCR amplified using the primer pair Arch1F/Arch1R (Cruaud et al., 2014) only from the dry extract, due to the little amount of archaeal biomass in the liquid and steam samples. Both bacterial and archaeal PCR amplifications were carried out according to standard procedures (Warren-Rhodes et al., 2018). Microbial communities were then identified by the construction of a paired-end amplicon library by means of Illumina MiSeq sequencing (Illumina Inc., San Diego, CA, United States). Raw sequence data were deposited at the NCBI Sequence Read Archive $\left(\mathrm{SRA}^{1}\right)$, under accession number PRJNA507699.

Raw sequences were processed either in the MOTHUR software v.1.39.5 (Schloss et al., 2009), using a custom script based upon MiSeq SOP (Kozich et al., 2013), or in R package 'phyloseq' (McMurdie and Holmes, 2013). Sequence reads were clustered into OTUs (Operational Taxonomic Units) at the 97\% similarity level. Datasets were rarefied independently by random selection to even sequencing depth, corresponding to the lesser number of sequences found in the samples (i.e., 40264 reads). Taxonomic affinities for the reads were assigned by comparison of OTUs representative sequences against RDP database (RDP reference files v.16; release 11, Cole et al., 2014). OTU's affinities reported as "cyanobacteria/chloroplast" were further assigned to a taxonomic identity by comparing them against $\mathrm{nr} / \mathrm{nt}$ (NBCI), EMBL, Greengenes and SILVA databases for more precise cyanobacteria taxonomic identification. The sequences assigned to "mitochondria" or "chloroplast" were removed from further analyses. The total number of OTUs was provided as an estimate of phylogenetic richness. Shannon's diversity index $\left(H^{\prime}\right)$ and Pielou's Evenness $(J$ ') based on OTU data were calculated on the three samples by means of R package 'vegan' (Oksanen et al., 2017). The same package was also used to perform a Correspondence Analysis (CA) between microbial classes and sinter samples.

\section{Multiplex Fluorescent Sandwich Microarray Immunoassay (FSMI)}

Powdered sinter samples were analyzed by fluorescent sandwich microarray immunoassays (FSMI) with the LDChip200 (i.e., Life Detector Chip; Parro et al., 2008a, 2011a), to interrogate a panel of about 200 polyclonal antibodies produced for

\footnotetext{
${ }^{1}$ http://www.ncbi.nlm.nih.gov/sra
}

binding with biological polymers and microbes from extant or well-preserved extinct life structures (Rivas et al., 2008). The LDChip200 used in this study contained 181 antibodies (purified IgG fraction) produced using as immunogens: (i) whole microbial cells from bacteria and archaea, (ii) spores from Grampositive bacteria, (iii) extracellular polymeric substances from cultures and environmental samples, (iv) environmental extracts (from soils, water, sediments, rocks, and biofilms) from extreme environments (Parro et al., 2011a; Blanco et al., 2017), (v) conserved proteins and peptides involved in key metabolisms (e.g., nitrogen fixation, nitrogen and sulfur reduction, energy metabolisms, iron storage, or PHAs (poly-hydroxyalkanoates) synthesis), and (vi) 36 preimmune sera (IgG fraction) as negative controls (for a detailed antibody information see Supplementary Table S1). The targets for the 181 antibodies used in this work are described elsewhere (Supplementary Table S1 in SánchezGarcía et al., 2018) and complemented with the antibodies listed in Supplementary Table S1 in this work. The purified immunoglobulin (IgG) fraction of each antibody was printed in a triplicate spot-pattern, fluorescently labeled with Alexa 647, checked, titrated and used as reported elsewhere (Rivas et al., 2008).

The LDChip200 is a shotgun antibody microarray immunosensor produced to increase the success of detecting any microbial remain in natural samples, either for environmental monitoring and/or for detecting signs of life in planetary exploration (Rivas et al., 2008; Parro et al., 2008b, 2011b, 2018). Limitations related to the presence of relatively complex molecules from abiotic origin in other planetary bodies, are being presently achieved by adding new antibodies for detecting molecules such as aromatic amino acids or polyaromatic hydrocarbons (Moreno-Paz et al., 2018). In continuous process of improvement, the LDChip is the core sensor of the already high TRL (Technology Readiness Level) instrument called SOLID (Signs of Life Detector), specially conceived for missions concept as the IceBreaker drilling of the Martian permafrost (McKay et al., 2013). The detailed protocol for the analysis of the sinter samples at El Tatio with the LDChip200 is described in Blanco et al. (2017). Briefly, up to $0.5 \mathrm{~g}$ of each sample were resuspended in $2 \mathrm{~mL}$ of TBSTRR buffer $(0.4 \mathrm{M}$ Tris- $\mathrm{HCl} \mathrm{pH} 8$, $0.3 \mathrm{M} \mathrm{NaCl}, 0.1 \%$ Tween 20), ultrasonicated and filtered through $5 \mu \mathrm{m}$. The filtrates were used as a multianalyte-containing sample for the FSMI as described in preceding works (Rivas et al., 2008; Blanco et al., 2012, 2017). The LDChip200 microarray images were analyzed and quantified by GenePix Pro Software (Molecular Devices, Sunnyvale, CA, United States). The final fluorescence intensity $(F)$ of each antibody spot was calculated as reported by Rivas et al. (2011). To minimize the probability of false positives, we increased the stringency by applying to all spots an additional cutoff value of 2.5 -fold the average of $F$ of the whole array (Blanco et al., 2015; see details on Supplementary Text S1).

In addition, the molecular abundance, richness, diversity, and evenness were also estimated. As all the immunoassays were performed on the same amount of sample and upon similar experimental and scanning conditions, the sum of fluorescence intensity in every positive antigen-antibody reaction for each 
sample was used as an estimation of the molecular abundance (Parro et al., 2011c), whereas the number of positive antigenantibody reactions was employed as an indirect measure of the sample richness. The molecular diversity was then determined through the Shannon Index $\left(H^{\prime}\right)$, according to the following equation:

$$
H^{\prime}=-\sum_{i=1}^{s}\left(p_{i} \log _{2} p_{i}\right)
$$

where $H^{\prime}$ defines the molecular diversity in the samples analyzed by the LDChip200; $s$ corresponds to the molecular richness (i.e., sample richness above) and $p_{i}$ is the partial diversity calculated as a rate between the fluorescence for each positive immuno-detection and the total fluorescent for each sample under analysis. Finally, the molecular evenness at each sample was then determined through the Pielou's evenness index $\left(J^{\prime}\right)$, according to the following equation:

$$
J^{\prime}=H^{\prime} / \ln S
$$

where $J$ ' defines Pielou's evenness index; $H^{\prime}$ corresponds to the molecular diversity in the samples analyzed by the LDChip200; and $\mathrm{S}$ matches to the molecular richness.

\section{RESULTS}

\section{Silica Sinter Lithofacies in the Three Sinter Mounds at EI Tatio}

Stereoscope and SEM images of the liquid mound and steam mound sinter samples in different orientations illustrated they consisted primarily of spicules characterized by parabolic laminations of vitreous clear or opaque opal-A. Supplementary Figure S1A shows a cross-sectional stereoscopic view of closely spaced spicules in the liquid mound sample. The inner core of the spicules comprised dense vitreous opal-A, which did not always appear laminated on fractured surfaces of the structures. The outermost opaque and tan laminations of the spicules, which contrasted with the clear inner core of the structures, revealed their downward parabolic orientation that was visible due to differences in their color. The more porous and bright white precipitate located between the spicules was the remnants of silicified microbial biofilms. SEM images of the top surface of the liquid mound sample revealed the presence of heavily silicified and intertwined filaments (Supplementary Figure S1B) and less-silicified remnants of short filaments and rods on the most recent accretionary surface of the sample (Supplementary Figure S1C). SEM images from the inside of this sample illustrated entombment of microbial remnants in opalA nanocolloids (Supplementary Figure S1D) and the remnants of exopolysaccharides (EPS) that are often preserved with a honeycomb-like structure on surfaces where microorganisms attached reversibly (leaving only EPS remnants) and irreversibly (leaving intertwined cellular remnants and EPS relicts) on exposed sinter surfaces (Supplementary Figure S1E).

Supplementary Figure S2A showed a top-down stereoscopic view of closely spaced spicules in the steam mound sample that were surrounded by the remnants of silicified biofilms and detrital grains. The downward parabolic laminations of the spicules were observed in this orientation as concentric laminae, once again distinguishable as variations in color (white, tan, and gray). A SEM image of the abrupt interface between the highly porous silicified biofilm and massive vitreous opal-A (Supplementary Figure S2B) suggested that once environmental conditions supported biofilm growth on the periphery of a spicule, that growth continued unabated until the structure was intermittently immersed in hydrothermal fluid, allowing spicular growth to resume. The pore space between closely spaced spicules in the steam sinter was completely filled with a combination of silicified biofilm and detrital grains of opal-A and accessory minerals. A SEM image of a spicule separated from the sample (Supplementary Figure S2C) showed relicts of silicified biofilm attached to the spicule surface and, occasionally, cellular remnants of bacteria that either colonized the spicular surfaces (Supplementary Figure S2D) or infiltrated the pore space of previously silicified remnants (Supplementary Figure S2E).

Supplementary Figure S3A showed a cross-sectional stereoscopic view of wavy laminations of opal-A in the sinter sample from the dry mound. A stereoscopic plan view of the dry mound sample (Supplementary Figure S3B) showed evidence of an irregular network of ridges. The wavy lamination visible in cross-section (Supplementary Figure S3A) is due to the ridge-like nature of the accretionary surface. An SEM image of this surface showed the well-preserved silicified remnants of a biofilm that consisted primarily of short filaments, rods, and the fibrils typical of dehydrated EPS (Supplementary Figure S3C). Heavily entombed filaments (Supplementary Figure S3D) and organically preserved remnants of a biofilm that consisted of cocci (Supplementary Figure S3E) were also found on the surfaces and in fractures of the dry sinter sample.

\section{Mineralogy and Bulk Geochemistry of the Three El Tatio Sinter Mounds}

The X-ray diffraction patterns produced by fragments of spicules and columns that were separated from the liquid and steam mound samples and from a non-porous, white region from the top of the dry sinter (Supplementary Figure S4) revealed that they consisted almost entirely of opal-A (Rodgers et al., 2004). As an aqueous precipitate, the mineraloid opal-A does not have a three-dimensional crystalline structure, yet the ubiquitous presence of randomly ordered silica tetrahedra produces a diffraction pattern that consists of a single broad feature centered on $23^{\circ} 2 \theta$ (ca. $3.9 \AA$ ), typical of X-ray amorphous materials. The matrix of the liquid and steam mounds consisted of fine-grained detrital material primarily formed from opal-A (Supplementary Figure S4) and the accessory phases quartz, halite, feldspar, clay minerals, and iron oxides (data from analysis at CAB, not shown). Distinct detrital layers with a similar accessory mineral inventory were also found in the dry mound sinter sample.

Ion chromatography (IC) showed the presence of diverse inorganic anions (Figure 2A), in the three sinter samples with variable content depending on the hydrothermal system (i.e., liquid, steam, or dry). Chloride was present in the three sinter 

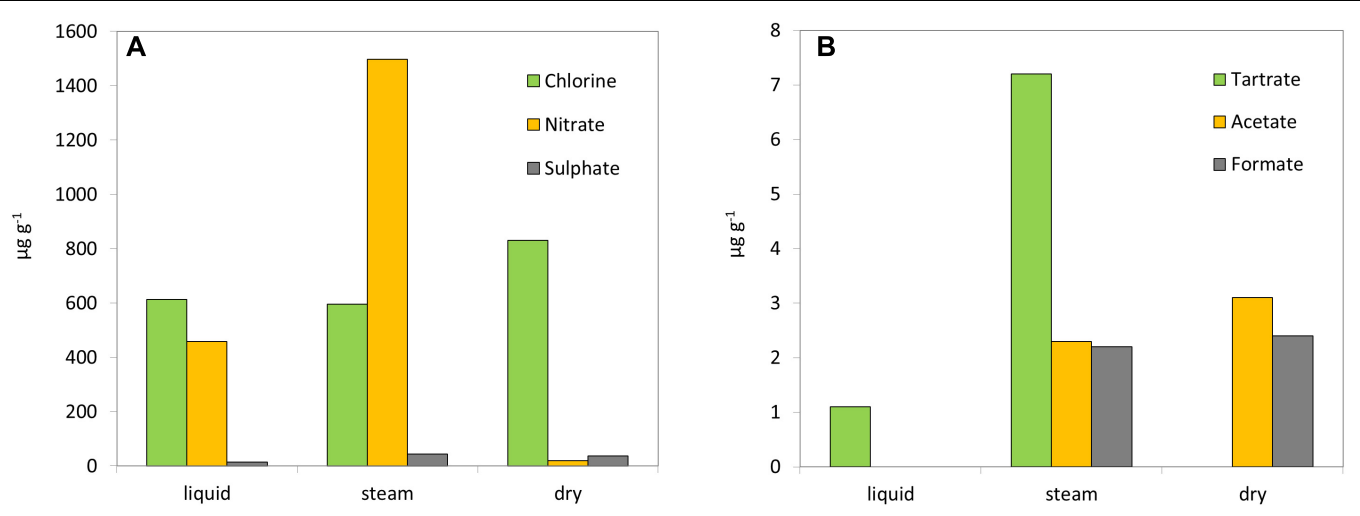

FIGURE 2 | Geochemical analysis. Concentration $\left(\mu \mathrm{g} \mathrm{g}^{-1}\right.$ ) of inorganic (A) and organic anions (B) in the three sinter mounds at El Tatio (liquid, steam, and dry).

extracts, with similarly high concentrations in the liquid $(612 \mu \mathrm{g}$ $\left.\mathrm{g}^{-1}\right)$ and steam $\left(596 \mu \mathrm{g} \mathrm{g}^{-1}\right)$ mound samples, and an even higher concentration in the dry one $\left(831 \mu \mathrm{g} \mathrm{g}^{-1}\right)$. Nitrate was present in the three systems, with the steam sample containing the largest concentration of all mounds and ions $\left(1497 \mu \mathrm{g} \mathrm{g}^{-1}\right)$ and the dry sample the lowest $\left(20 \mu \mathrm{g} \mathrm{g}^{-1}\right)$. In fact, nitrate and chloride concentrations were inversely related among the three mounds. Sulfate was measured in low concentrations $\left(<45 \mu \mathrm{g} \mathrm{g}^{-1}\right)$ in all samples, as well as fluoride $\left(<20 \mu \mathrm{g} \mathrm{g}^{-1}\right)$ (Supplementary Table S2). The water collected from the liquid mound contained higher concentrations of chloride $\left(7068 \mu \mathrm{g} \mathrm{g}^{-1}\right)$, sulfate ( $346 \mu \mathrm{g}$ $\left.\mathrm{g}^{-1}\right)$, fluoride $\left(12 \mu \mathrm{g} \mathrm{g}^{-1}\right)$, and bromide $\left(56 \mu \mathrm{g} \mathrm{g}^{-1}\right)$ compared to its sinter deposits (Supplementary Table S2).

In addition to the inorganic anions, three light organic acids were detected by IC (Figure 2B). Acetate and formate were present at similarly low concentrations $\left(<2.5 \mu \mathrm{g} \mathrm{g}^{-1}\right)$ in the extracts from the steam and dry sinter samples, but not detected in that of the liquid mound sample. Conversely, extracted tartrate was measured at higher concentration in the steam $\left(7.2 \mu \mathrm{g} \mathrm{g}^{-1}\right)$ than the liquid $\left(1.1 \mu \mathrm{g} \mathrm{g}^{-1}\right)$ samples, but was not detected in the dry sample. The water sample from the liquid mound was measured to contain only tartrate, which was present in very high concentration $\left(286 \mathrm{\mu g} \mathrm{ml}^{-1}\right)$ (Supplementary Table S2).

The content of TOC $(0.07-0.10 \%)$ and TN $(0.01-0.04 \%)$ varied little between the three sinter samples (Table 1), with the dry mound showing the lowest values of both elements. The resulting TOC over TN ratios $(\mathrm{C} / \mathrm{N})$ varied from 3 to 7 . The biomass isotopic ratios $\delta^{13} \mathrm{C}$ and $\delta^{15} \mathrm{~N}$ ranged from -15.7 to $-24.0 \%$ and from -0.9 to $5.4 \%$, respectively (Table 1 ). The steam sinter sample showed the most depleted $\left(\delta^{13} \mathrm{C}\right)$ and enriched $\left(\delta^{15} \mathrm{~N}\right)$ isotopic composition.

\section{Molecular Distribution of Lipid Biomarkers in the Three Sinter Mounds}

Several lipid families were detected in the three sinter samples, with a generalized larger abundance of the functionalized lipid groups. The most abundant class of lipids were the linear carboxylic acids (i.e., $n$-carboxylic acids), which concentration ranged from 2.35 to $2.71 \mu^{g^{-1}}$ (Table 1). The molecular distribution of the $n$-carboxylic acids showed chain lengths
TABLE 1 | Bulk geochemical composition of the sinter samples from the three mounds at El Tatio.

\begin{tabular}{|c|c|c|c|}
\hline & Liquid & Steam & Dry \\
\hline TOC (\% dw) & 0.10 & 0.10 & 0.07 \\
\hline TN (\% dw) & 0.02 & 0.04 & 0.01 \\
\hline$\delta^{13} \mathrm{C} \mathrm{OC}(\%)$ & -15.9 & -24.0 & -15.7 \\
\hline$\delta^{15} \mathrm{~N}$ TN $(\% 0)$ & -0.9 & 5.4 & -1.1 \\
\hline $\mathrm{C} / \mathrm{N}$ & 5 & 3 & 7 \\
\hline$n$-alkanes & 0.05 & 0.08 & 0.05 \\
\hline Branched alkanes $^{a}$ & 0.11 & 0.14 & 0.04 \\
\hline Octadecene $\left(\mathrm{C}_{18: 1}\right)$ & n.d. & 0.04 & n.d. \\
\hline Hentriacontatriene $\left(\mathrm{C}_{31: 3}\right)$ & n.d. & 0.01 & n.d. \\
\hline$n$-carboxylic acids & 2.53 & 2.71 & 2.35 \\
\hline Unsaturated carboxylic acids ${ }^{\mathrm{b}}$ & 0.39 & 0.34 & 0.23 \\
\hline Dicarboxylic acids ${ }^{\mathrm{C}}$ & 0.06 & 0.05 & 0.03 \\
\hline Iso-/anteiso carboxylic acids ${ }^{d}$ & 0.71 & 0.38 & 0.24 \\
\hline Other branched carboxylic acids ${ }^{\mathrm{e}}$ & 0.11 & 0.02 & 0.01 \\
\hline Cyclopropyl acids ${ }^{f}$ & n.d. & n.d. & 0.03 \\
\hline$n$-alkanols & 1.40 & 1.12 & 1.81 \\
\hline Stigmastanol & 0.12 & 0.13 & 0.06 \\
\hline$\beta$-sitosterol & 0.01 & 0.04 & n.d. \\
\hline Cholesterol & n.d. & 0.01 & 0.17 \\
\hline Pristane & 0.05 & 0.12 & n.d. \\
\hline Phytane & 0.21 & 0.35 & n.d. \\
\hline Squalane & n.d. & n.d. & 0.003 \\
\hline Crocetane & n.d. & n.d. & 0.002 \\
\hline
\end{tabular}

Concentration $\left(\mu \mathrm{g} \mathrm{g}^{-1}\right)$ and compositional distribution of lipid biomarkers. ${ }^{a}$ Sum of mono-methyl, di-methyl and tri-methyl alkanes. ${ }^{b}$ Sum of mono- and di-unsaturated carboxylic acids between 16 and 19 carbon units. 'Sum of dicarboxylic acids between 6 and 10 carbon units. ${ }^{d}$ Sum of iso and anteiso carboxylic acids between 15 and 19 carbon units. ${ }^{e}$ Sum of other mono-methyl (MM) carboxylic acids. ${ }^{f}$ Sum of cyclopropyl $C_{17}$ and $C_{19}$ acids. Please go to Supplementary Figures S5-S8 for consulting individual concentrations of the (normal, branched, and other) carboxylic acids, alkanols, and alkanes families.

ranging from $\mathrm{C}_{8}$ to $\mathrm{C}_{30}$, a clear dominance of the even carbons, maximum at $\mathrm{C}_{16}$ or $\mathrm{C}_{18}$, and secondary groups at $\mathrm{C}_{22}$ to $\mathrm{C}_{26}$ (Supplementary Figure S5). After the straight-chained congeners, the most abundant carboxylic acids were those with branches at iso- and/or anteiso- positions $\left(0.24-0.71 \mu \mathrm{g} \mathrm{g}^{-1}\right)$, 
followed by the unsaturated (0.23-0.39 $\left.\mu \mathrm{g} \mathrm{g}^{-1}\right)$, dicarboxylic (0.03-0.06 $\left.\mu \mathrm{g} \mathrm{g}^{-1}\right)$, and cyclopropyl (0.03 $\left.\mu \mathrm{g} \mathrm{g}^{-1}\right)$ congeners (Figure 3). Iso and anteiso carboxylic acids of 13 to 19 carbon units were found in the three sinter samples (Supplementary Figure S6), with more of the iso/anteiso- $\mathrm{C}_{18}$ in the liquid and dry mounds. Carboxylic acids with one or two unsaturations were generally measured at chain lengths of $\mathrm{C}_{16}(16: 1 \omega 7$, and 16:1 $\omega 9), \mathrm{C}_{17}(17: 1 \omega 6), \mathrm{C}_{18}(18: 1 \omega 9$, and 18:2 $\omega 6,9)$, and $\mathrm{C}_{19}$ $(19: 1 \omega 9)$ (Supplementary Figures S6D-F). Dicarboxylic acids of short chain $\left(\mathrm{C}_{6}\right.$ to $\left.\mathrm{C}_{10}\right)$ and branched carboxylic acids other than iso/anteiso congeners (i.e., monomethyl acids, MM) were found to be minority congeners in the acidic fractions (Figure 3 ). Cyclopropyl $\mathrm{C}_{17}$ and $\mathrm{C}_{19}$ acids were only detected in the dry sinter sample at a total concentration of $0.03 \mu \mathrm{g} \mathrm{g}^{-1}$ (Table 1).

Other functionalized lipids, the straight chain alkanols (i.e., $n$-alkanols), were found at chain lengths between $\mathrm{C}_{10}$ and $\mathrm{C}_{29}$, and concentrations ranging from 1.12 to $1.81 \mu^{g^{-1}}$ (Table 1). Similarly to the $n$-carboxylic acids, the molecular distribution of the $n$-alkanols showed a markedly even character dominated by the $\mathrm{C}_{16}$ and $\mathrm{C}_{18}$ congeners (Supplementary Figure S7). Together with the linear alkanols, two phytosteroids ( $\beta$-sitosterol and stigmastanol), and cholesterol were identified within the polar fraction (Table 1). The largest amount of cholesterol was measured in the sinter sample from the inactive, dry mound.

In contrast to the functionalized lipids, saturated hydrocarbons were less abundant in the three sinter samples (Table 1). Branched alkanes including mono-, di-, and trimethyl ramifications were detected at one order of magnitude larger concentration (0.11-0.14 $\left.\mu \mathrm{g} \mathrm{g}^{-1}\right)$ than the $n$-alkanes (0.05-0.08 $\left.\mu \mathrm{g} \mathrm{g}^{-1}\right)$ in the liquid and steam sinter samples. In the dry mound, the concentration of branched and $n$-alkanes was similar. The $n$-alkanes distribution ranged in the three sinter samples from $\mathrm{C}_{10}$ to $\mathrm{C}_{33}$, and showed different maximum peaks at $\mathrm{C}_{17}$ (liquid mound), $\mathrm{C}_{15}$ (steam mound), or $\mathrm{C}_{25}$ (dry mound) (Supplementary Figures S8A-C). Among the branched alkanes, the mono-methyl congeners $\left(\mathrm{C}_{15}, \mathrm{C}_{17}\right.$, and $\left.\mathrm{C}_{18}\right)$ were the most abundant in all sinter samples (Supplementary Figures S8D-F), especially in the steam mound. Other branched alkanes of isoprenoid configuration were detected at variable concentrations among the sinter samples. Pristane and phytane were present in the liquid and steam mounds, whereas the dry sinter contained only small traces of squalane and crocetane (Table 1). Low concentrations of octadecene $\left(\mathrm{C}_{18: 1}\right)$ and hentriacontatriene $\left(\mathrm{C}_{31: 3}\right)$ were also found in the steam sinter sample (Table 1).

\section{Isotopic Distribution $\left(\delta^{13} \mathrm{C}\right)$ of Lipid Biomarkers in the Three Sinter Mounds}

The compound-specific carbon isotopic ratio of alkanes, carboxylic acids and alkanols showed certain trends between the samples (Figure 4). The $n$-alkanes $\delta^{13} \mathrm{C}$ values ranged from -22.5 to $-31.3 \%$ in the three sinter samples, with a general depletion with increasing number of carbon units, and from the liquid to the dry mound (Figure 4A). In the liquid sinter sample, a clear enrichment was observed for the $\mathrm{C}_{17}(-22.9 \%)$ and $\mathrm{C}_{19}(-22.5 \%)$ relative to the remaining $n$-alkanes. The $\delta^{13} \mathrm{C}$ composition of the $n$-carboxylic acids ranged from -20.5 to $-36.1 \%$ (Figure $4 B$ ), with an even clearer depletion with increasing carbon units and a marked enrichment of the odd relative to the even carbons. The compoundspecific isotopic ratio of other acids could only be achieved for a few iso/anteiso, unsaturated, and cyclopropyl congeners (Supplementary Table S3). The iso/anteiso and unsaturated acids contained generally homogeneous $\delta^{13} \mathrm{C}$ ratios, whereas the cyclopropyl $\mathrm{C}_{17}$ and $\mathrm{C}_{19}$ acids only found in the dry mound were relatively enriched (Figure 4D). Only three members of the $n$-alkanols family $\left(\mathrm{C}_{14}, \mathrm{C}_{16}\right.$, and $\left.\mathrm{C}_{18}\right)$ were detectable for their ${ }^{13} \mathrm{C}$ content (Supplementary Table S3). The three samples showed similar $\delta^{13} \mathrm{C}$ values for the $\mathrm{C}_{14}\left(-27.4\right.$ to $-27.6 \%$ ) and $\mathrm{C}_{16}$ $(-27.7$ to $-28.4 \% 0) n$-alkanols, whereas a distinct composition was observed for the $\mathrm{C}_{18}$ congener in the liquid $(-24.8 \% 0)$, steam $(-27.7 \% 0)$, and dry $(-30.2 \%)$ samples (Figure 4C). Overall, all lipid groups showed a depleting trend in the ${ }^{13} \mathrm{C}$ composition from the liquid to the dry mound.

\section{Microbial Diversity Based on DNA Analysis}

Phylogenetic analysis of environmental 16S rRNA gene amplicon sequences showed that almost $70 \%$ of total bacterial reads
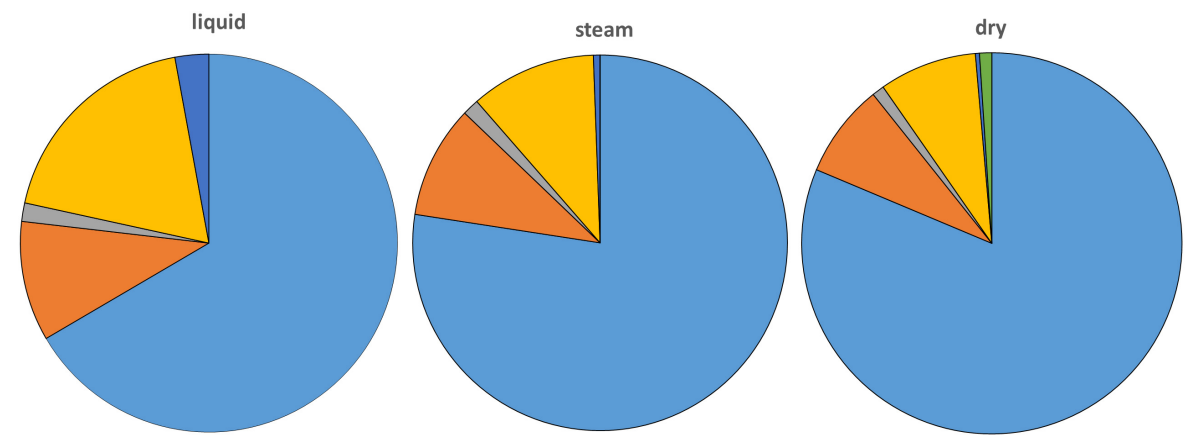

$\square$ Linear

口Unsaturated

$\square$ Dicarboxylic

$\square$ Iso/anteiso

$\square$ Branched

$\square$ Cyclopropane

FIGURE 3 | Relative amount (\%) of carboxylic acids (linear and saturated, or normal; unsaturated; dicarboxylic; iso/anteiso; other branched; and cyclopropyl) in the three sinter mounds at El Tatio. "Unsaturated" includes mono- and di-unsaturated carboxylic acids, whereas "other branched" covers middle chain mono-methyl carboxylic acids. 
U. $n$-alkanes

$\begin{array}{llllllllllllllll}\vdash & 16 & 17 & 18 & 19 & 20 & 21 & 22 & 23 & 24 & 25 & 26 & 27 & 28 & 29 & 30\end{array}$

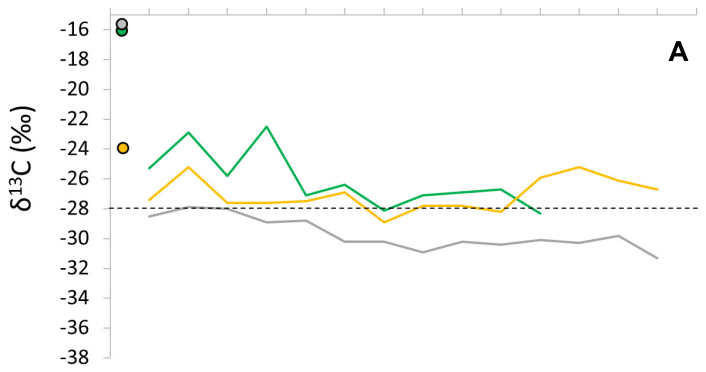

n-alkanols

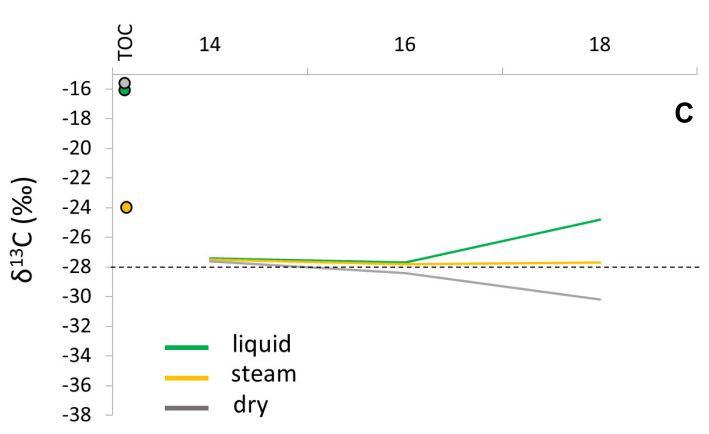

$n$-carboxylic acids

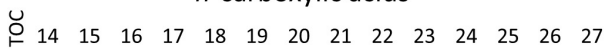

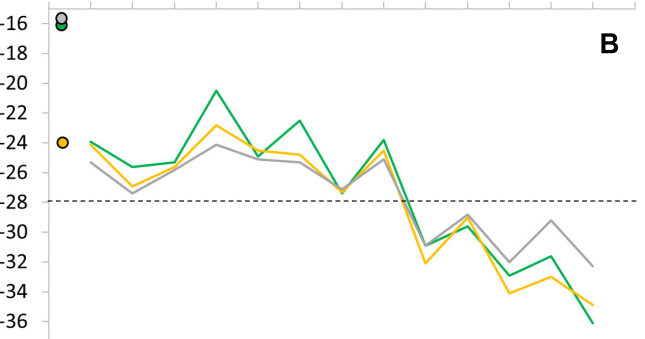

other carboxylic acids

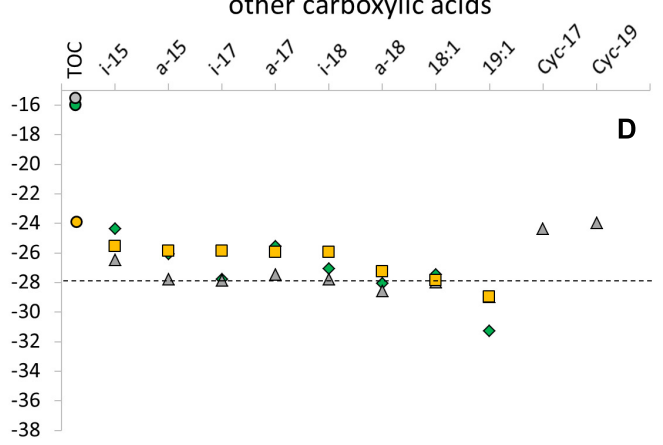

FIGURE 4 | Compound-specific isotopic composition $\left(\delta^{13} \mathrm{C}\right.$ ) of specific lipid families in the three sinter mounds (liquid, steam, and dry); $n$-alkanes (A), $n$-carboxylic acids (B), $n$-alkanols (C), and iso/anteiso-, unsaturated, and cyclopropyl (Cyc 17:0 and Cyc 19:0) acids (D). The bulk isotopic ratio of the total biomass (i.e., relative to TOC) was also depicted for the three samples as full circles. A dashed line was provided in each panel to facilitate the visualization of the $\delta^{13} \mathrm{C}$ shifts observed (mostly) in the $n$-carboxylic acids.
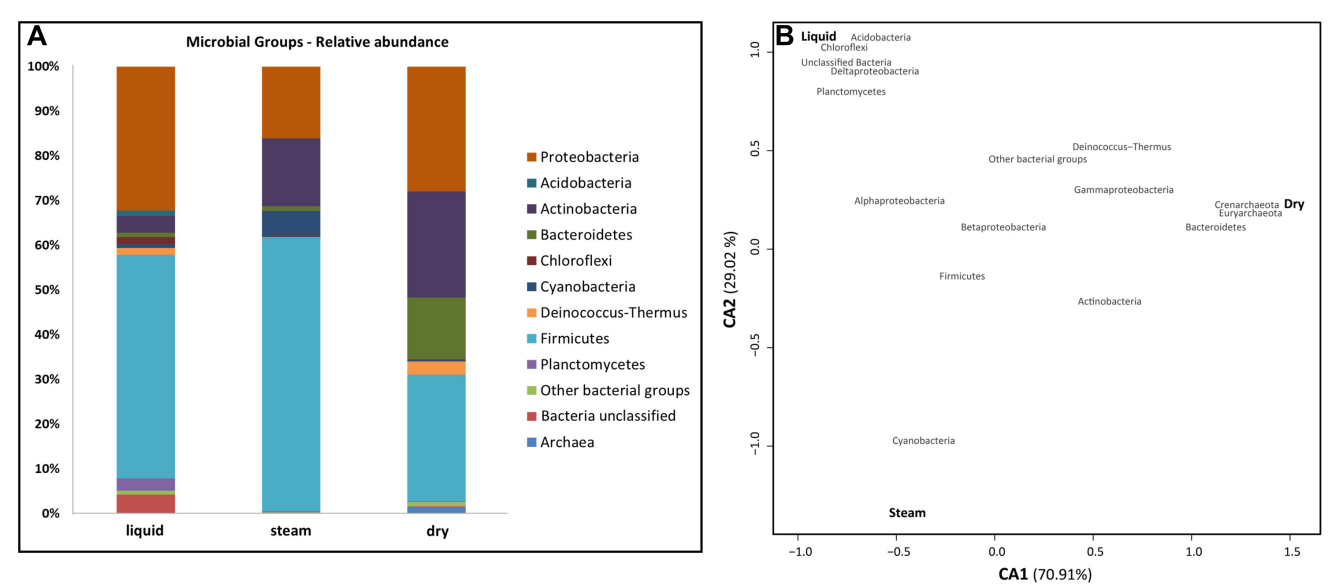

FIGURE 5 | Comparison of microbial groups in the sinter samples from the three mounds at El Tatio (A), and Correspondence Analysis (CA) between the main microbial groups (red) and the sampling sites (black) (B). In a, the microbial groups inferred from DNA analysis are expressed as relative abundance. Bacillales and Clostridiales (Firmicutes), Rhodobacteriales, Rhizobiales, Burkholderiales and Desulfuromonadales (Proteobacteria), as well as Actinomycetales (Actinobacteria) were the most represented orders within the most abundant bacterial phyla. In b, CA1 ( $X$ axis) accounted for $70.90 \%$ of total variability explained by the model, and CA2 (Y axis) for $29.02 \%$. The closer clustering of microbial groups to a sampling site is, the more characteristic these groups are at the site. Distance among sampling sites depicts compositional differences in them.

in the El Tatio sinter geysers belonged to the Firmicutes and Proteobacteria phyla (Figure 5A). The low GC Gram-positive Firmicutes were mainly found in the liquid and steam sinter samples, which showed a closer correspondence than the dry sample to that phylum (Figure 5B). Bacillales (Bacilli) and
Clostridiales (Clostridia), together accounting for more than $80 \%$ of the Firmicutes' sequences, were the most frequently represented orders. Proteobacterial classes were generally more abundant in the liquid mound, especially Alphaproteobacteria $(17.6 \%$ in liquid mound versus 9.2 and $2.5 \%$ in steam and 
dry mounds, respectively). In contrast, Gammaproteobacteria were more represented in the dry (22\% of total sequences) than in the liquid (9.9\%) and steam (3.9\%) mounds, as the correspondence analysis illustrated (Figure 5B). The orders Rhodobacteriales and Rhizobiales (Alphaproteobacteria), Burkholderiales and Hydrogenophilales (Betaproteobacteria), Desulfuromonadales (Deltaproteobacteria), as well as Vibrionales and Xanthomonadales (Gammaproteobacteria) together accounted for $70 \%$ of the total proteobacterial sequences.

The Actinobacteria (mainly Actinomycetales), Bacteroidetes (Cytophagales and Flavobacteriales), and Cyanobacteria together accounted for the $22 \%$ of the total number of sequences found in the sinter samples (Figure 5A). Actinobacteria and Bacteroidetes were particularly abundant in the dry mound (23.7 and 13.9\% of sample sequences, respectively), whereas Cyanobacteria was more prevalent $(5.9 \%)$ in the steam mound sample (associations illustrated in Figure 5B). In contrast, Acidobacteria, Chloroflexi, and Planctomycetes each accounted for $>1 \%$ of the sequences only in the liquid sinter (Figure 5B). The Deinococcus-Thermus class is of special interest as it was observed to be similarly representative of both the liquid (1.7\% of total sequences) and dry $(2.9 \%)$ mounds (Figure 5B), with sequences only belonging to Thermales and Deinococcales orders, respectively.

Archaeal sequences were recovered only in the dry sample (Figure 5A). They accounted for $<2 \%$ of overall diversity in these samples and comprised taxa from just two classes: Halobacteria (Euryarchaeota) and Thermoprotei (Crenarchaeota) (Figure 5B).

The OTU-richness varied from 78 in the steam sample to 142 in the dry sample (Figure 6B). The Shannon diversity index $\left(H^{\prime}\right)$ of the microbial communities at OTU level showed increasing values from the liquid (1.7) to the steam (2.3) and dry (3.3) samples (Figure 6C), concurrently with the Pielou's Evenness index ( $J^{\prime}$ of $0.38,0.52$, and 0.67 , respectively) based on the OTU data (Figure 6D).

\section{Microbial Mass and Biomarkers Detected by a Multiplex Immunoassay}

The LDChip200 revealed the presence in the sinter samples of biomolecules recognized by antibodies produced against iron and sulfur oxidizing bacteria and crude environmental extracts from biofilms of the Río Tinto area (Supplementary Figure S9) such as Leptospirillum ferrooxidans, Acidithiobacillus spp. and others (Amils et al., 2002). The immunoassays also detected positive immuno-signals against metal, sulfate and perchlorate reducers, bacteroidetes, actinobacteria including spore-forming bacteria, cyanobacteria, the thermo-aquifical sulfur oxidizer Hydrogenobacter thermophilus as well as methanogenic, thermophilic and halophilic archaea. In addition, positive immuno-detections were revealed with antibodies to proteins related to nitrogen fixation, energy metabolisms, thermal and hydric stress, poly-hydroxyalkanoates (PHAs) synthesis and sulfate and nitrate reduction (Supplementary Figure S9). Detection of chemolithoautotrophs involved in the use of sulfur and iron (Figure 7 and Supplementary Figure S9) revealed the occurrence of sulfur-iron metabolism, where sulfur and iron oxidizers could proliferate in oxygen-rich microniches, while metal (mainly iron) reducers occupied anaerobic microregions with organic matter available for oxidizing in parallel to the metal reduction.

A heat map showing the fluorescence intensity of the positive immuno-detections (Figure 7) displayed relative differences in the composition of the microbial community in the three sinter mounds. Chemolithoautotrophs involved in the oxidation of sulfur (Acidithiobacillus spp.), and oxidation (Leptospirillum sp. and Acidimicrobium sp.) or reduction of iron (Acidocella sp., Acidiphilium sp., and Shewanella spp.) were more abundant in the liquid and steam samples. These sinter samples (mostly the steam one) were also richer than the dry sample in primary producers such as benthic (Anabaena sp., Leptolyngbya sp., and Tolypothrix sp.) and endolithic (Chroococcidiopsis sp.) cyanobacteria, consistent with the higher detection of nitrogen fixation proteins (i.e., Nif and chaperon HscA; Figure 7). Sulfate reducers were also detected in higher intensity in the steam and (mostly) liquid samples, through antibodies to Desulfovibrio sp. and Desulfosporosinus sp., as well as to the DsrA protein. In addition, positive immuno-detections of archaeal strains such as Methanobacterium sp., Pyrococcus sp. or Halorubrum sp., accounting for methanogenic and heterotrophic metabolisms, were only observed in the liquid and steam samples. In contrast, the dry sinter recorded the highest immuno-signals against (i) bacteria capable of perchlorate reduction (Magnetospirillum sp., Ideonella sp. and Dechlorobacter sp.), (ii) an aquifical bacterium (Hydrogenobacter thermophilus), and (iii) proteins related to the synthesis of PHAs (Figure 7).

The sum of fluorescence intensity decreased from the liquid to the dry mound by a factor of ca. 5 (Figure 6A), indicating that the dry sample contained lower biomass or that target microbial markers were transformed or degraded with time. The declining number of positive immuno-signals from the liquid $(n=39)$ to the dry $(n=13)$ sample resulted in parallel decreasing trends of the molecular richness (Figure 6B) and diversity (Figure 6C) toward the less active mound. In contrast, the Pielou's evenness showed a somewhat increasing trend with the loss of hydrothermal activity (Figure 6D).

\section{DISCUSSION}

\section{Mineralogical, Geochemical, and Morphological Features in the Three Sinter Mounds at EI Tatio}

The mineralogical composition of the sinter samples was similar in the three geyser mounds, with amorphous silica phases (i.e., opal-A) dominating the three XRD spectra (Supplementary Figure S4). The shift of the strongest feature (3.9 $\AA)$ to slightly higher d-spacing $(3.93 \AA)$ for the dry sinter relative to the liquid and steam sinters suggested a more dense packing of $\mathrm{SiO}_{4}$ tetrahedra in the dry sinter, consistent with dehydration. In the liquid and steam mounds, the sinter deposit was composed of spicular or columnar geyserite, which typically forms under conditions of intermittent inundation and splashing at temperatures $>80^{\circ} \mathrm{C}$ (Walter, 1976; Cady and Farmer, 1996; 


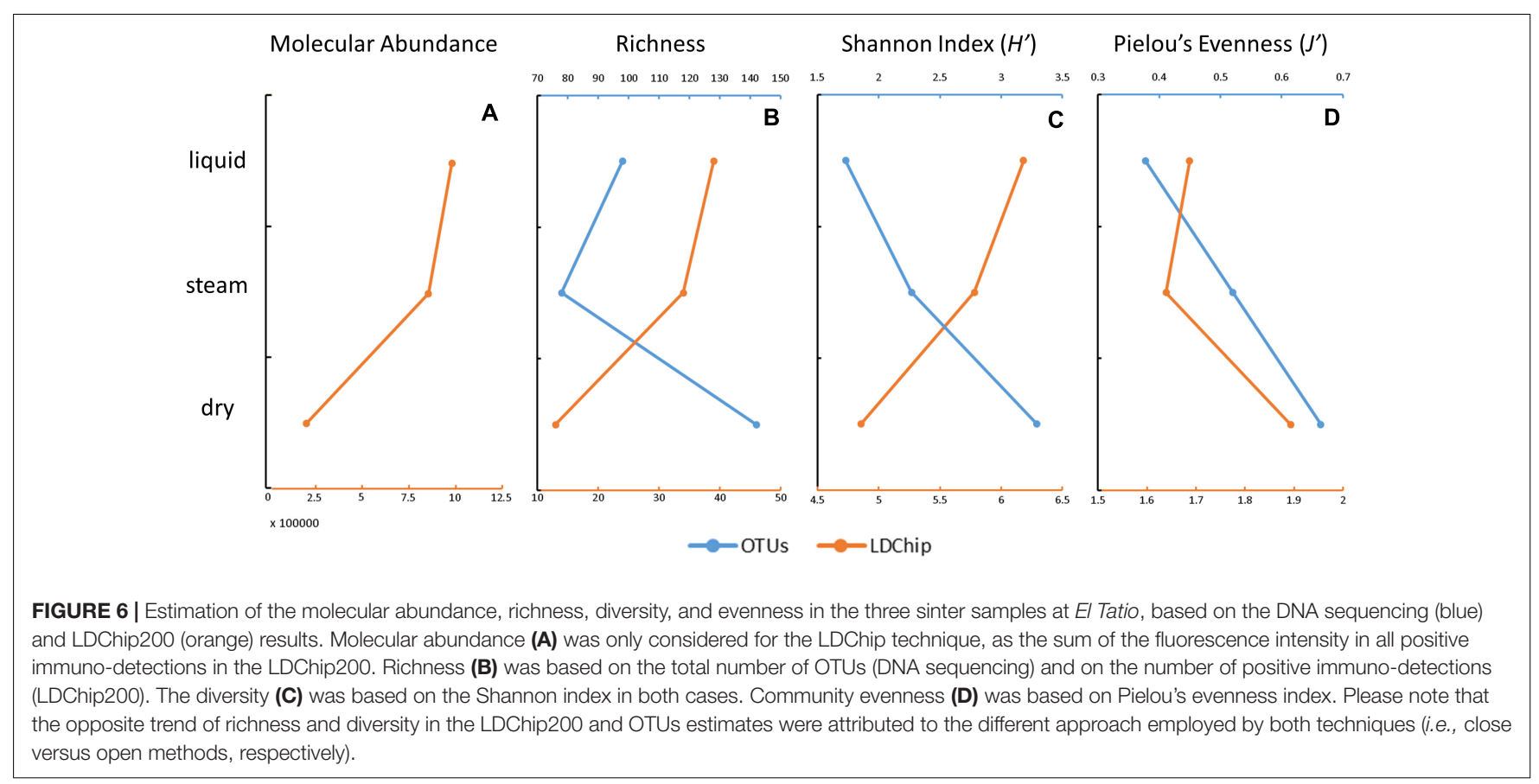

Braunstein and Lowe, 2001). Evaporative salts and accessory minerals contribute to the tan and gray color of the matrix. The accessory mineral inventory is most likely wind-blown material from the volcanic country rock that surrounds the hydrothermal basin (Nicolau et al., 2014). Differences in the amounts of such detrital phases incorporated during accretion, often give these layers the appearance of being laminated. Yet these interlayers have an important role in defining the environmental conditions that define the habitat in each mound.

A geochemical difference among the mounds complements the mineralogical observations. The driest mound would be expected to have the most evaporative salt and, indeed, a higher concentration of chloride was found in the dry mound than in the other two samples (Figure 2A). The progressive wettingdrying cycles that would occur during waning geyser activity would likely concentrate salts evaporatively from the chloriderich hydrothermal fluid. The biofabric of the dry sinter sample was consistent with this interpretation of prolonged periods of dryness at this inactive mound. During periods when the geyser mound was active, the relatively flat-to-wavy laminated sinter fabric would have developed when accretionary surfaces were perpetually wet and immersed in liquid for long periods of time. Continuous inundation would preclude spicule formation, which occurs on splashy, intermittently dry surfaces. A comparison of the random network of ridges on the outer surface of the dry sinter (Supplementary Figure S3) developed during the waning stages of geyser activity. That is, spicules develop in evaporative settings, ridges develop when there is intermittent wetting, and flat and wavy laminations develop when flow is continuous. These three environments are visible in the organic compositions and microbial populations as well.

The morphological characteristics of the biofabrics of the three sinter samples confirmed that the liquid and steam mounds displayed gross morphological and biofabric evidence of having formed in an intermittently wetted environment. Under such conditions, fluid is typically drawn by capillary action to topographical highs on the sinter due to rapid evaporation at the apices of spicular protrusions (Cady and Farmer, 1996). Walter (1976) was the first to describe spicular and columnar geyserites formed along the rims and edges of hot springs in Yellowstone National Park (United States) and he attributed their morphology to episodic splashing at the nearby pool. At El Tatio, spicular geyserite structures occurred on the tops and sides of the liquid and steam mounds in distinct regions that appeared to be associated with either (i) intermittent fluid flow from the top of the erupting liquid geyser mound or (ii) from a region within the base of the steam mound that was engulfed in steam from hot fluid inside the sinter cone at the base of the structure. Regardless of the distribution of these structures on the top, side, or base of the mounds, the liquid and steam spicules grew outward from the mounds with their apices pointing away from and perpendicular to their accretionary surfaces. In contrast, the wavy laminated biofabric of the dry mound sinter lacked well-developed spicules. We interpret the absence of the spicules on this part of the dry mound as an indication that, when the geyser was more active, fluid flow was likely more persistent and flowed over the sinter for longer periods of time during its formation.

\section{Microbial Transition Through Different Stages of Hydrothermal Activity at El Tatio}

The different geochemical, mineralogical, and morphological features of the three sinter mounds were accompanied by distinct molecular (lipids and immuno-detections) and genomic biopatterns, which allowed us to describe a biogeochemical 


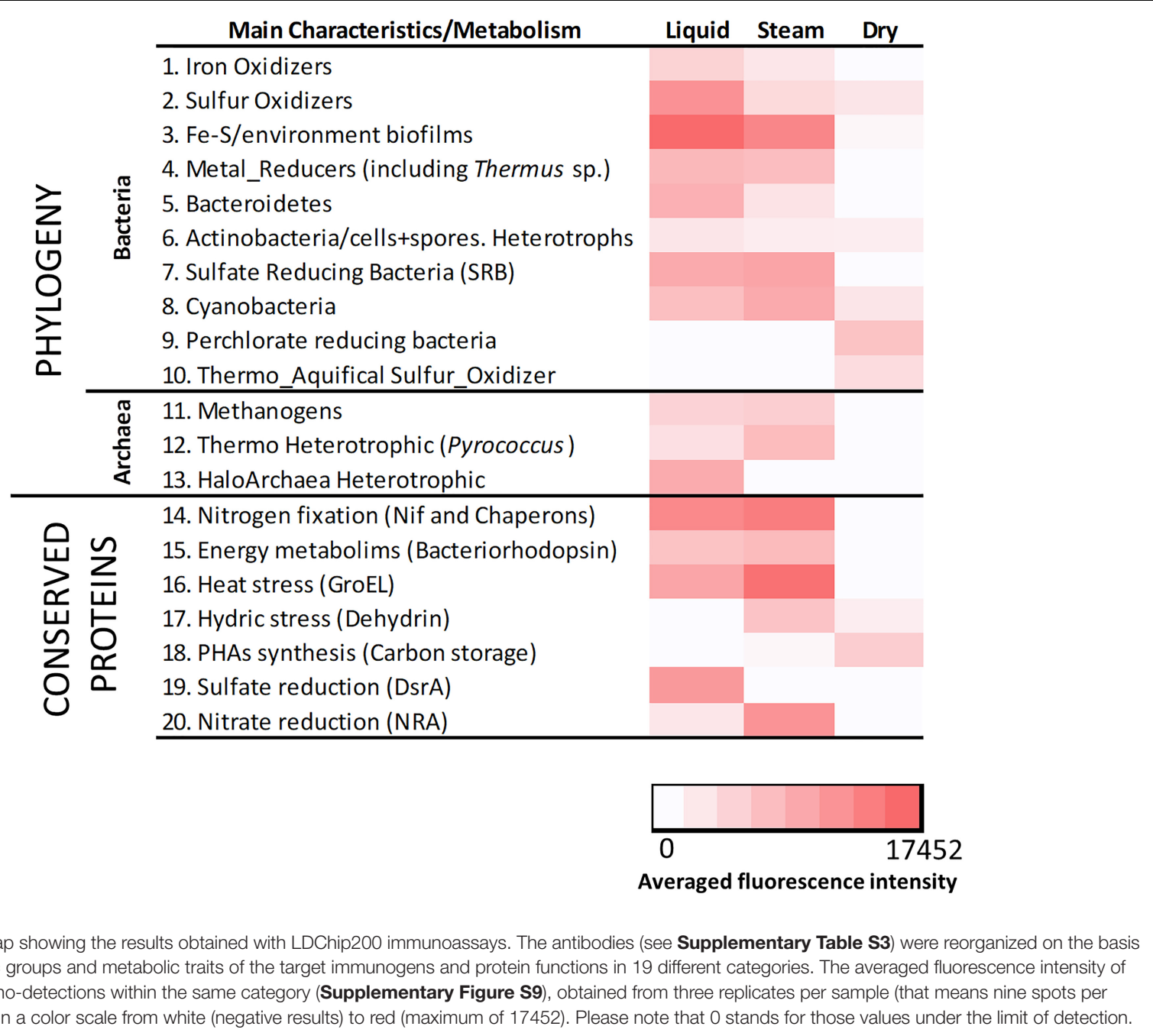

transition (prokaryotic-signatures based) along the hydrothermal activity gradient (Figure 8). Despite the ubiquitous dominance of Firmicutes and Proteobacteria in the three systems, the relative abundance of certain phylogenetic groups and specific biomarkers made a difference in the microbial composition at the three stages of hydrothermal activity. For instance, in the hydrothermally active liquid mound, the microbial community was observed to show a strong correspondence with phylogenetic groups such as Chloroflexi or Deltaproteobacteria. The detection of chlorophyll-derived lipids, such as pristane and phytane (Table 1), supported the contribution of photosynthetic microorganisms such as Chloroflexi to the community. Pristane and phytane are isoprenoid compounds mainly originating from phytol (Brocks and Summons, 2003), the esterifying alcohol of phototrophic chlorophylls (Didyk et al., 1978), although additional sources such as biphytane, archaeols or even tocopherol in the case of phytane, have been also described (Brocks and Summons, 2003). As for Proteobacteria, the detection by the LDChip200 of certain members such as Desulfuromonadales and Desulfovibrio sp., coincided with other against the Firmicutes Desulfosporosinus sp., suggesting the occurrence of sulfate reduction in the liquid, as well as steam, mound. In the liquid sample in particular, that detection agreed with the greater signal from sulfate reduction protein DsrA (Figure 7) and a larger detection of iso/anteisocarboxylic groups (Figure 3) also associated with sulfate reducing bacteria (SRB), particularly the $C_{15}$ and $C_{17}$ pairs (Langworthy et al., 1983). In the absence of measurement of other sulfur species in the samples, the removal of sulfate by sulfate reducers (and/or less sulfate in the hydrothermal fluid at different times) would explain the lower concentration of this anion in the liquid sample (Figure 2A), accompanied by metabolic processes that utilized the only organic anion available to donate electrons in this geothermal system (i.e., tartrate; Figure 2B). Low molecular-weight organic acids such as tartrate are excellent energy sources for anaerobic microbial metabolisms (e.g., Menes and Muxí, 2002; Maune and Tanner, 2012) such as sulfate reduction and methanogenesis (Parro et al., 2018).

Another distinctive molecular feature of the liquid mound was the larger concentration of dicarboxylic acids relative to the other two systems (Table 1), which may be attributed to the presence 


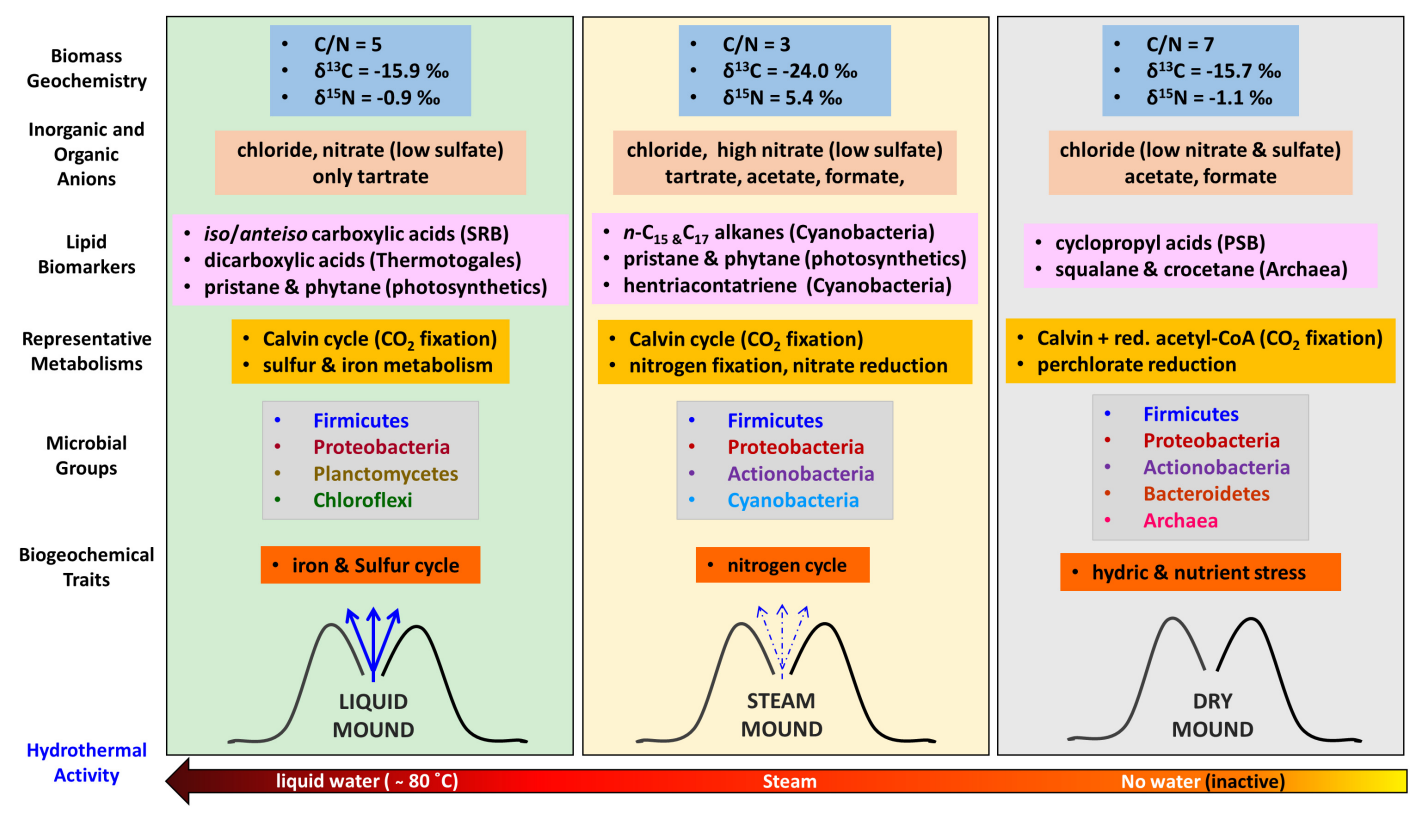

FIGURE 8 | Schematic of the biogeochemical reconstruction of the three geothermal systems (liquid, steam, and dry) at El Tatio as a function of the hydrothermal activity based on bulk elemental and isotopic geochemistry, characteristic lipid biomarkers (source diagnosis in brackets), compound-specific isotopic analysis (metabolism), DNA sequencing (phylogeny), and LDChip immunoassays (phylogeny, metabolism, and biogeochemical traits). SRB means Sulfur Reducing Bacteria, GnSB Green non-Sulfur Bacteria, and PSB Purple Sulfur Bacteria. Red, acetyl-CoA stands for the reductive acetyl-CoA pathway for autotrophic CO 2 fixation.

of thermophiles or hyperthermophiles, typically containing additional external protective membranes. Comparative distributions of dicarboxylic acids of slightly longer $\left(C_{16}\right.$ to $\left.C_{22}\right)$ or much longer $\left(\mathrm{C}_{30}\right.$ to $\left.\mathrm{C}_{32}\right)$ chains were described by Carballeira et al. (1997) in cultures of hyperthermophiles such as Pyrococcus furiosus and Thermotoga maritima, respectively. In the present study, the somewhat decreasing trend in concentration of the dicarboxylic acids from the liquid to the dry mound sample (Figure 3) was consistent with the selective disappearance of thermophiles from the hottest (i.e., intermittent water at $\sim 80^{\circ} \mathrm{C}$ ) to the coolest (i.e., dry) setting.

Microbial metabolism in the liquid mound sample was dominated by the Calvin cycle, along with lesser sulfur and iron chemolithotrophic pathways. Autotrophic metabolism (Hayes, 2001) was supported by a large fractionation (i.e., 11 to $26 \%$; Quandt et al., 1977; Preu $\beta$ et al., 1989) of $\delta^{13} \mathrm{C}$ values relative to atmospheric $\mathrm{CO}_{2}$ (ca. $-8 \%$; Graven et al., 2017). Indeed, relatively light $\delta^{13} \mathrm{C}$ values $(-21$ to $-36 \%$ ) were measured in the liquid sample for the carboxylic acids, $n$-alkanes, and $n$-alkanols (Figure 4). Complementarily, chemolithoautotrophs using sulfur-iron metabolism (Figure 7) were detected in different microenvironments, where heterotrophic metal (mainly iron) reducers would occupy anaerobic micro-regions, while sulfur and iron oxidizers would proliferate either in anaerobic or oxygen-rich microniches. In this case, the accessory minerals and dissolved ions would provide the metal and sulfur needed to support this community. Biofilms and EPS contributing to layering in the spicules observed in the sample (Supplementary Figure S1) may have aided to the isolation of these microenvironments.
In the steam mound, the strongest correspondence of the microbial community was observed with Cyanobacteria (Figure 5B). The relative enrichment of these microorganisms in this mound was consistently suggested by the relatively larger concentration of different cyanobacteria lipidic markers, such as mid-chain-length mono- and di-methyl alkanes (Dembitsky et al., 2001), octadecene (Shiea et al., 1991; Campbell et al., 2015), or unsaturated carboxylic acids (i.e., 16:1 $\omega 7$, 18:1 $\omega 9$, or 18:2 $\omega 6$; Cohen et al., 1995; Allen et al., 2010; Pagès et al., 2015; Table 1 and Supplementary Figures S6, S8). In agreement, the LDChip detected in this sample a relatively higher signal of biomaterial immunologically associated with Anabaena sp., Leptolyngbya sp., Tolypothrix sp., and Chroococcidiopsis sp. (Figure 7 and Supplementary Figure S9). In the steam system, Cyanobacteria seem to play an important role in the metabolism that supports the microbial community and possibly in the structures that formed under intermittent drier conditions.

Metabolically speaking, the steam sinter mound appeared largely influenced by the nitrogen cycle. The relatively larger immuno-signals of nitrogen fixation proteins (Nif and related Chaperons such as the HscA protein; Figure 7), together with the highest concentration of nitrate in the steam mound extract (Figure 2A), indicated that organisms capable of $\mathrm{N}_{2}$ fixation and subsequent initiation of nitrification, such as Cyanobacteria or the alphaproteobacterial order Rhizobiales, were active in the hydrothermally intermittent system. Additionally, the presence of the nitrate reductase protein (NRA in Figure 7) suggested that nitrate-reducing microorganisms could be making the most of the nitrate as an energetic source to thrive in the steam mound. Oxidation of organic matter (Chin and Janssen, 2002) or other 
inorganic compounds (e.g., $\mathrm{H}_{2}$ or sulfides) would assist with nitrate reduction. The distinctly high nitrate concentration in the steam sinter extract corresponded to morphological changes in the biofilms that developed in the interstices between the spicules. This shift in the microbial population is supported by the change to highly porous and silicified remnants observed in the interstices (Supplementary Figure S2). The presence of nitrate would also serve as a substrate for denitrification processes, which would be consistent with the highest detection of nitrate reductase (Figure 7) and the exclusive detection of nitrite in the steam sinter (Supplementary Table S2). In either case, the molecular evidence indicated that, together with autotrophic Calvin pathways (Figure 4), nitrogen cycle was a crucial metabolic trait in the microbial biofilm of the steam mound, where nitrate appeared as a central metabolite of different, co-occurring metabolic pathways.

The microbial community in the dry mound showed a strong correspondence with Archaea, Gammaproteobacteria, and Actinobacteria (Figure 5B). The relative abundance of Actinobacteria, a phylum with great adaptability to aridity and resistance to hydric stress and UV radiation (Makarova et al., 2001), coincided with the positive immuno-detections of proteins related to hydric stress (i.e., DhnA1 peptide from a dehydrin protein; Supplementary Figure S9), consistent with the limited access to water in the inactive geothermal system. In addition, the LDChip detected compounds indicative of nutritional stress conditions such as PHAs (Figure 7), which are produced upon need for carbon storage under nutritional stress or high $\mathrm{C} / \mathrm{N}$ ratios (Steinbüchel, 1991; Byrom, 1994). The episodic waning of geyser activity in the history of sinter accretion coincides with the scarcity of water and bioavailable nutrients, which would subsequently lead to hydric and nutritional stress. Indeed, the most abundant Firmicutes orders in the dry mound (i.e., Bacillales and Clostridiales) corresponded to microorganisms characteristically resistant to extreme conditions (e.g., desiccation and oxidative stress), including those able to form endospores (Paredes-Sabja et al., 2011) as an adaption for desiccation and oxidative stress.

Gammaproteobacteria was also particularly representative of the dry-mound microbial community (Figure 5B). Within them, purple sulfur bacteria (PSB) appeared to be present, according to the detection of low concentration (Table 1) of $\mathrm{C}_{17}$ and $\mathrm{C}_{19}$ cyclopropyl acids (Bühring et al., 2014) with $\delta^{13} \mathrm{C}$ values (Figure 4D) in the range of those assigned to PSB (from -20 to $-29 \%$ ) in microbial mats from, e.g., Shark Bay (Pagès et al., 2015). Cyclopropane carboxylic acids are bacterial membrane components typically transformed from unsaturated carboxylic acids when exposed to stressful conditions such as oxidants, starvation, or desiccation (Grogan and Cronan, 1997; Chen and Gänzle, 2016). Their formation decreases the permeability of bacterial membranes, enhancing their stability under environmental stress (Poger and Mark, 2015). Wilhelm et al. (2018) reported detection of these carboxylic acids in surface soils from hyperarid regions of the Atacama Desert at about $430-480 \mathrm{~km}$ southwest of the El Tatio geysers field (Chañaral and Altamira). In the present study, their detection only in the dry sample may be a response to an adaptive strategy against desiccation and exposure to higher radiation in the inactive sinter geyser.

The closest correspondence of the dry sample was with Euryarchaeota and Crenarchaeota (Figure 5B). The contribution from archaeal sources solely in the dry mound was consistent with the detection of squalane and crocetane only in that sample (Table 1), respectively, attributed to halophylic (ten Haven et al., 1988) or methanogenic/methanotrophic archaea (Brocks and Summons, 2003). The lack of archaeal signal in the dry sample by the LDChip200 was attributed to intrinsic limitations on the technique, in relation to the absence of antibodies against the specific archaeal strains detected here by DNA sequencing. The LDChip200 is an assay interrogating a panel of 181 polyclonal antibodies (i.e., close method), in contrast to the ability of the DNA sequencing in detecting any existing phylogenetic group (i.e., open method). Furthermore, the antibodies used in the LDChip were produced using whole cell lysates of particular strains or whole EPS fractions as immunogens. This means that each polyclonal antibody preparation may contain subpopulations of antibody molecules recognizing their target with different specificities and affinities. They can bind epitopes from a variety of microorganisms, not necessarily the same species, but related ones, or even to others well conserved among large phylogenetic groups. Consequently, a direct correlation at species level between LDChip and DNA sequences should not be expected. This is a drawback of the LDChip, yet it increases the chances for detecting any microbial remains in life detection experiments.

Finally, certain occurrence of perchlorate reduction activity was considered in the dry mound, as suggested by the LDChip200 detection against Proteobacteria capable of perchlorate reduction such as Magnetospirillum sp., Ideonella sp, and Dechlorobacter sp. (Supplementary Figure S9). Despite the detection of markers by the LDChip, the presence of perchlorate reducing indicators in the dry sinter should be further investigated, since no perchlorate anions were detected in the samples. Whether these microorganisms are indeed using minor amounts of perchlorate as electron acceptor (Nepomnyashchaya et al., 2012) or they are only detoxifying photochemically generated chloride species (Trumpolt et al., 2005) has to be determined. As for $\mathrm{CO}_{2}$ fixation, the consistent depletion $\left(\sim 2-4 \%\right.$ ) of the $\delta^{13} \mathrm{C}$ ratios in the majority of lipid compounds in the dry sample relative to the other two mounds (Figure 4) suggested a shift in the metabolic fingerprint that could be related to water scarcity. Even though the Calvin cycle may still dominate the autotrophic metabolism in the dry sample $\left(\delta^{13} \mathrm{C}\right.$ values from -24 to $-32 \%$ ), the general decrease in compound-specific $\delta^{13} \mathrm{C}$ ratios may be caused by some contribution from assimilation pathways with larger ${ }^{13} \mathrm{C}$ fractionations (i.e., reductive acetyl-CoA pathway; Fuchs, 1989; Preu $\beta$ et al., 1989).

The microbial community in the three sinter mounds showed a transition through the different stages of hydrothermal activity, with the dry mound displaying generally larger alpha-diversity estimates (Figure 6), that is, a richer, more diverse and even population. Although the opposite trend was observed in some of the LDChip-based estimates (i.e., richness and Shannon's diversity), the discrepancy was attributed to known factors, such 
as (i) the differences in approach underlying the LDChip200 and DNA sequencing techniques (i.e., closed versus open methods), and (ii) the fact that the drier the sample, the lower the biomass to analyze, which can reduce the concentrations of many target molecules to values below the limit of detection for the LDChip200. The consistently greatest Pielou's index values in the dry sample illustrated the impact of the decreasing hydrothermal activity in the microbial community structure. Greater evenness is generally correlated with less active communities and is consistent with the dormant stage of the dry sinter mound (i.e., inactive geyser). A hydrothermally active geyser, such as the liquid water-engulfed sinter mound at $\mathrm{El}$ Tatio, is initially colonized (primary community) by microorganisms able to endure and thrive at high temperatures (i.e., thermophiles and hyperthermophiles). The reduced group of taxa capable to establish in such high temperature results in a microbial community of low richness, diversity and evenness. As hydrothermal activity wanes and dry periods lengthen (i.e., the steam-wetted and dry sinter mounds at El Tatio), temperature ceases to be a key factor and thermophiles became less competitive compared to other microbial communities. Opportunistic microorganisms comprising endoliths and communities contributed by environmental contaminants emerge overprinting the primary thermophiles (secondary community). While approaching dormancy, the inactive, dry geyser displayed the richest, most diverse and most even microbial community composed of members and metabolisms that survived the waning of geyser activity.

\section{CONCLUSION}

The multidisciplinary field and molecular study was successful in explaining the influence of the degree of hydrothermal activity on the biomarkers record (i.e., including present and past biosignatures) in the three morphologically similar geyser mounds at El Tatio. In the context of the ecological and environmental setting, the phylogenetic, molecular, and metabolic patterns, in agreement with differences in the micronscale morphology of the geyserite, followed a hydrodynamic gradient predictable during the lifetime of a geyser mound; the transition from persistent hydrothermal activity to intermittent steam exposure to episodic and eventually, continual dryness. Accordingly, the microbial population shifted from primary communities adapted to high temperature (thermophiles and hyperthermophiles) to populations adopting protective strategies

\section{REFERENCES}

Abrajano, T. A., Murphy, D. E., Fang, J., Comet, P., and Brooks, J. M. (1994). $13 \mathrm{C} / 12 \mathrm{C}$ ratios in individual fatty acids of marine mytilids with and without bacterial symbionts. Org. Geochem. 21, 611-617. doi: 10.1016/0146-6380(94) 90007-8

Allen, M. A., Neilan, B. A., Burns, B. P., Jahnke, L. L., and Summons, R. E. (2010). Lipid biomarkers in hamelin pool microbial mats and stromatolites. Org. Geochem. 41, 1207-1218. doi: 10.1016/j.orggeochem.2010. 07.007 against desiccation and increased exposure to intense UV radiation as geyser activity waned. Alpha-diversity estimates supported the transition toward a richer and more even microbial population with the waning of the hydrothermal activity. Our results demonstrated the effectiveness of integrating microbiological and biogeochemical approaches to document and understand the microbial community structure and function in high-altitude geothermal environments with resemblance to Hesperian surfaces on Mars. Gathering data about the capability of different analytical techniques to decipher information from preserved fossil biosignatures is of vital importance for future astrobiological missions.

\section{AUTHOR CONTRIBUTIONS}

DC, NC, KW-R, and NH collected the sinter samples. DC and LS-G extracted and analyzed the lipidic fractions and wrote the manuscript. MF-M, SP, KL, KW-R, MB, and DL-B extracted DNA performed DNA sequencing and discussed phylogenetic results. MG-V, YB, and VP performed and analyzed the LDChip200 immunoassays. MG-V and VP performed ion chromatography analysis. VP, SC, NH, KW-R, and SP contributed to improve the manuscript edition.

\section{FUNDING}

This work was funded by the Spanish Ministry of Economy and Competitiveness (MINECO/FEDER) projects no. RYC-201419446, CGL2015-74254-JIN, and ESP2015-69540-R, and NASA Astrobiology Institute NAI-CAN7 project no. NNX15BB01A.

\section{ACKNOWLEDGMENTS}

We acknowledge the Complejo Turístico Tatio Mallku (Chile) for allowing access and sampling. We thank Paloma MartínezSarmiento for stable isotopes analysis and Maria Teresa Fernández-Sampedro for XRD analysis at CAB.

\section{SUPPLEMENTARY MATERIAL}

The Supplementary Material for this article can be found online at: https://www.frontiersin.org/articles/10.3389/fmicb. 2018.03350/full\#supplementary-material

Amils, R., González-Toril, E., Fernández-Remolar, D., Gómez, F., Rodríguez, N., and Durán, C. (2002). Interaction of the sulfur and iron cycles in the tinto river ecosystem. Rev. Environ. Sci. Biol. 1, 299-309. doi: 10.1023/A:1023232002312

Barbieri, R., Cavalazzi, B., Stivaletta, N., and López-García, P. (2014). Silicified biota in high-altitude geothermally influenced ignimbrites at El Tatio geyser field, andean cordillera (Chile). Geomicrobiol. J. 31, 493-508. doi: 10.1080/01490451. 2013.836691

Blanco, Y., Gallardo-Carreño, I., Ruiz-Bermejo, M., Puente-Sánchez, F., Cavalcante-Silva, E., Quesada, A., et al. (2017). Critical assessment of analytical techniques in the search for biomarkers on mars: a mummified 
microbial mat from antarctica as a best-case scenario. Astrobiology 17, 984-996. doi: 10.1089/ast.2016.1467

Blanco, Y., Moreno-Paz, M., Aguirre, J., and Parro, V. (2015). "Multiplex Fluorescent Antibody Microarrays and Antibody Graphs for Microbial and Biomarker Detection in the Environment," in Hydrocarbon and Lipid Microbiology Protocols. Chapter 159, eds T. J. McGenity, K. N. Timmis, and B. Nogales (Heidelberg: Springer), doi: 10.1007/978-3-662-45179-3

Blanco, Y., Prieto-Ballesteros, O., Gómez, M. J., Moreno-paz, M., GarcíaVilladangos, M., Rodríguez-Manfredi, J. A., et al. (2012). Prokaryotic communities and operating metabolisms in the surface and the permafrost of deception island (Antarctica). Environ. Microbiol. 14, 2495-2510. doi: 10.1111/ j.1462-2920.2012.02767.x

Braunstein, D., and Lowe, D. R. (2001). Relationship between spring and geyser activity and the deposition and morphology of high temperature ( $>73$ degrees C) siliceous sinter, Yellowstone National Park, Wyoming, USA. J. Sediment. Res. 71, 747-763. doi: 10.1306/2dc40965-0e47-11d7-8643000102c1865d

Brock, T. D. (1978). Thermophilic Microorganisms and Life at High Temperatures. New York, NY: Springer-Verlag. doi: 10.1007/978-1-4612-6284-8

Brocks, J. J., and Summons, R. E. (2003). “Sedimentary hydrocarbons, biomarkers for early life," in Biogeochemistry: Treatise on Geochemistry, Vol. 8, ed. W. H. Schlesinger (Oxford: Elsevier Pergamon), 63-115.

Bühring, S. I., Kamp, A., Wörmer, L., Ho, S., and Hinrichs, K.-U. (2014). Functional structure of laminated microbial sediments from a supratidal sandy beach of the GermanWadden Sea (St. Peter-Ording). J. Sea Res. 85, 463-473. doi: 10.1016/j. seares.2013.08.001

Byrom, D. (1994). "Polyhydroxyalkanoates," in Plastic from Microbes: Microbial Synthesis of Polymers and Polymer Precursors, ed. D. P. Mobley (Munich: Hanser), 5-33.

Cady, S. L., and Farmer, J. D. (1996). Fossilization processes in siliceous thermal springs: trends in preservation along thermal gradients. Ciba Found. Symp. 202, $150-173$.

Cady, S. L. S., Skok, J. R., Gulick, V. G., Berger, J. A., and Hinman, N. W. (2018). "Siliceous hot spring deposits: Why they remain key astrobiologial targets," in From Habitability to Life on Mars, eds N. A. Cabrol and E. A. Grin (Edmond, OK: Elsevier Science), 179-210.

Campbell, K. A., Lynne, B. Y., Handley, K. M., Jordan, S., Farmer, F. D., Guido, D. M., et al. (2015). Tracing biosignature preservation of geothermally silicified microbial textures into the geological record. Astrobiology 15, 858-882. doi: $10.1089 /$ ast.2015.1307

Carballeira, N. M., Reyes, M., Sostre, A., Huang, H., Verhagen, M. F. J. M., and Adams, M. W. W. (1997). Unusual fatty acid compositions of the hyperthermophilic archaeon Pyrococcus furiosus and the Bacterium Thermotoga maritima. J. Bacteriol. 179, 2766-2768. doi: 10.1128/jb.179.8.27662768.1997

Castenholz, R. W. (1973). "Ecology of blue-green algae in hot springs," in The Biology of Blue-Green Algae, eds N. G. Carr and B. A. Whitton (Hoboken, NJ: Blackwell Scientific Publications Ltd), 379-414.

Chen, Y. Y., and Gänzle, M. G. (2016). Influence of cyclopropane fatty acids on heat, high pressure, acid and oxidative resistance in Escherichia coli. Int. J. Food Microbiol. 222, 16-22. doi: 10.1016/j.ijfoodmicro.2016.01.017

Chin, K.-J., and Janssen, P. H. (2002). Propionate formation by Opitutus terrae in pure culture and in mixed culture with a hydrogenotrophic methanogen and implications for carbon fluxes in anoxic rice paddy soil. Appl. Environ. Microbiol. 68, 2089-2092. doi: 10.1128/AEM.68.4.2089-2092.2002

Cohen, Z., Margheri, M. C., and Tomaselli, L. (1995). Chemotaxonomy of cyanobacteria. Phytochemistry 40, 1155-1158. doi: 10.1016/0031-9422(95) 00335-5

Cole, J. R., Wang, Q., Fish, J. A., Chai, B., McGarrell, D. M., Sun, Y., et al. (2014). Ribosomal database project: data and tools for high throughput rRNA analysis. Nucleic Acids Res. 42, D633-D642. doi: 10.1093/nar/gkt1244

Cruaud, P., Vigneron, A., Lucchetti-Miganeh, C., Ciron, P. E., Godfroy, A., and Cambon-Bonavita, M. A. (2014). Influence of DNA extraction method, 16S rRNA targeted hypervariable regions, and sample origin on microbial diversity detected by 454 pyrosequencing in marine chemosynthetic ecosystems. Appl. Environ. Microbiol. 80, 4626-4639. doi: 10.1128/AEM.00592-14

Damer, B., and Deamer, D. (2015). Coupled phases and combinatorial selection in fluctuating hydrothermal pools: a scenario to guide experimental approaches to the origin of cellular life. Life Basel 5, 872-887. doi: 10.3390/life501 0872

Deamer, D. W., and Georgiou, C. D. (2015). Hydrothermal conditions and the origin of cellular life. Astrobiology 15, 1091-1095. doi: 10.1089/ast.2015.1338

Dembitsky, V. M., Dor, I., Shkrob, I., and Aki, M. (2001). Branched alkanes and other apolar compounds produced by the cyanobacterium microcoleus vaginatus from the negev desert. Russ. J. Bioorgan. Chem. 27, 110-119. doi: 10.1023/A:1011385220331

Didyk, B. M., Simmoneit, B. R. T., Brassell, S. C., and Eginton, G. (1978). Organic geochemical indicators of palaeoenvironmental conditions of sedimentation. Nature 272, 216-222. doi: 10.1038/272216a0

Dunckel, A. E., Bayani-Cardenas, M., Sawyer, A. H., and Bennett, P. C. (2009). High-resolution in-situ thermal imaging of microbial mats at El Tatio geyser, chile shows coupling between community color and temperature. Geophys. Res. Lett. 36:L23403. doi: 10.1029/2009GL041366

Farmer, J. D., and Des Marais, D. J. (1999). Exploring for a record of ancient martian life. J. Geophys. Res. 104, 26977-26995. doi: 10.1029/1998je00 0540

Fernandez-Turiel, J. L., Garcia-Valles, M., Gimeno-Torrente, D., SaavedraAlonso, J., and Martinez-Manent, S. (2005). The hot spring and geyser sinters of El Tatio. Northern Chile Sediment. Geol. 180, 125-147. doi: 10.1016/j.sedgeo. 2005.07.005

Fouke, B. W., Farmer, J. D., Des Marais, D. J., Pratt, L., Sturchio, N. C., Burns, P. C., et al. (2000). Depositional facies and aqueous-solid geochemistry of travertinedepositing hot springs (Angel Terrace, Mammoth Hot Springs, Yellowstone National Park, USA). J. Sediment. Res. 70, 565-585. doi: 10.1306/2dc409290e47-11d7-8643000102c1865d

Fournier, R. O. (1989). Geochemistry and dynamics of the Yellowstone National Park Hydrothermal System. Annu. Rev. Earth Planet. Sci. 177, 13-53. doi: 10.1146/annurev.ea.17.050189.000305

Fournier, R. O., and Rowe, J. J. (1977). Solubility of amorphous silica in water at high-temperatures and high-pressures. Am. Mineral. 62, 1052-1056.

Fuchs, J. (1989). “Alternative pathways of autotrophic CO2 fixation,” in Autotrophic Bacteria, eds H. G. Schlegel and D. Bowien (Madison, WI: Science Tech), 365-382.

Giggenbach, W. F. (1978). The isotopic composition of waters from the El Tatio geothermal field, Northern Chile. Geochim. Cosmochim. Acta 42, 979-988. doi: 10.1016/0016-7037(78)90287-9

Giovannoni, S. J., Revsbech, N. P., Ward, D. M., and Castenholz, R. W. (1987). Obligately phototrophic Chloroflexus: primary production in anaerobic hot spring microbial mats. Arch. Microbiol. 147, 80-87. doi: 10.1007/BF0049 2909

Glennon, J. A., and Pfaff, R. (2003). The extraordinary thermal activity of the $E l$ Tatio geysers, Antofagasta Province, Chile. Trans. Geyser Obs. Study Assoc. 8, $31-78$.

Goin, J. C., and Cady, S. L. (2009). Biosedimentological processes that produce hot spring sinter biofabrics: examples from the Uzon caldera, Kamchatka Russia. Cell. Origin Life Ext. 12, 159-179.

Graven, H., Allison, C. E., Etheridge, D. M., Hammer, S., Keeling, R. F., Levin, I., et al. (2017). Compiled records of carbon isotopes in atmospheric CO2 for historical simulations in CMIP6. Geosci. Model Dev. 10, 4405-4417. doi: 10. 5194/gmd-10-4405-2017

Grogan, D. W., and Cronan, J. E. (1997). Cyclopropane ring formation in membrane lipids of bacteria. Microbiol. Mol. Biol. Rev. 61, 429-441.

Hayes, J. M. (2001). Fractionation of the Isotopes of Carbon and Hydrogen in Biosynthetic Processes. National Meeting of the. Boston, MA: Geological Society of America, 2-4. doi: 10.1515/9781501508745-006

Herlemann, D. P., Labrenz, M., Jürgens, K., Bertilsson, S., Waniek, J. J., and Andersson, A. F. (2011). Transitions in bacterial communities along the 2000 $\mathrm{km}$ salinity gradient of the Baltic Sea. ISME J. 5, 1571-1579. doi: 10.1038/ismej. 2011.41

Jahnke, L. L., Eder, W., Huber, R., Hope, J. M., Hinrichs, K. U., Hayes, J. M. et al. (2001). Signature lipids and stable carbon isotope analyses of octopus spring hyperthermophilic communities compared with those of aquificales representatives. Appl. Environ. Microbiol. 67, 5179-5189. doi: 10.1128/AEM.67. 11.5179-5189.2001 
Jones, B., Renaut, R. W., and Rosen, M. R. (2001). Biogenicity of gold-and silverbearing siliceous sinter forming in hot $\left(75^{\circ} \mathrm{C}\right)$ anaerobic spring-waters of Champagne Pool, Waiotapu, North Island, New Zealand. J. Geol. Soc. 158, 895-912. doi: 10.1144/0016-764900-131

Kato, K., Kobayashi, T., Yamamoto, H., Nakagawa, T., Maki, Y., and Hoaki, T. (2004). Microbial mat boundaries between chemolithotrophs and phototrophs in geothermal hot spring effluents. Geomicrobiol. J. 21, 91-98. doi: 10.1080/ 01490450490266334

Kaur, G., Mountain, B. W., Stott, M. B., Hopmans, E. C., and Pantcost, R. D. (2015). Temperature and $\mathrm{pH}$ control on lipid composition of silica sinters from diverse hot springs in the Taupo Volcanic Zone, New Zealand. Extremophiles 19, 327-344. doi: 10.1007/s00792-014-0719-9

Konhauser, K. O., Jones, B., Reysenbach, A. L., and Renaut, R. W. (2003). Hot spring sinters: keys to understanding Earth's earliest life forms. Can. J. Earth Sci. 40, 1713-1724. doi: 10.1139/e03-059

Konhauser, K. O., Phoenix, V. R., Bottrell, S. H., Adams, D. G., and Head, I. M. (2001). Microbial-silica interactions in Icelandic hot springs sinter: possible analogues for some-Precambrian siliceous stromatolites. Sedimentology 48, 415-434. doi: 10.1046/j.1365-3091.2001.00372.x

Kozich, J. J., Westcott, S. L., Baxter, N. T., Highlander, S. K., and Schloss, P. D. (2013). Development of a dual-index sequencing strategy and curation pipeline for analyzing amplicon sequence data on the MiSeq Illumina sequencing platform. Appl. Environ. Microbiol. 79, 5112-5120. doi: 10.1128/AEM.01043-13

Lacap, D. C., Barraquio, W., and Pointing, S. B. (2007). Thermophilic microbial mats in a tropical geothermal location display pronounced seasonal changes but appear resilient to stochastic disturbance. Environ. Microbiol. 9, 3065-3076. doi: 10.1111/j.1462-2920.2007.01417.x

Lahsen, A., and Trujillo, P. (1976). "El Tatio Geothermal Field," in Proceedings of the 2nd United Nations Symposium on Geothermal Fields, California.

Langworthy, T. A., Holzer, G., Zeikus, J. G., and Tornabene, T. G. (1983). Iso- and anteiso-branched glycerol diethers of the thermophilic anaerobe thermodesulfotobacterium commune. Syst. Appl. Micrbiol. 4, 1-17. doi: 10. 1016/S0723-2020(83)80029-0

Lau, C. Y. Y., Aitchison, J. C. C., and Pointing, S. B. B. (2008). Early colonization of thermal niches in a silica-depositing hot spring in central Tibet. Geobiology 6, 136-146. doi: 10.1111/j.1472-4669.2007.00124.x

Lynne, B. Y. (2015). Impact of three common post-depositional environmental settings on siliceous sinter diagenesis: an eight year experiment. J. Volcanol. Geotherm. Res. 292, 84-101. doi: 10.1016/j.jvolgeores.2015.01.007

Madigan, M. T. (1986). Chromatium tepdium sp. nov., a thermophilic photosynthetic bacterium of the family Chromatiaceae. Int. J. Syst. Bacteriol. 36, 222-227. doi: 10.1099/00207713-36-2-222

Makarova, K. S., Aravind, L., Wolf, Y., Tatusov, R. L., Minton, K. W., Koonin, E. V., et al. (2001). Genome of the extremely radiation-resistant bacterium Deinococcus radiodurans viewed from the perspective of comparative genomics. Microbiol. Mol. Biol. Rev. 65, 44-79. doi: 10.1128/MMBR.65.1.44-79. 2001

Maune, M. W., and Tanner, R. S. (2012). Description of Anaerobaculum hydrogeniformans sp. nov., an anaerobe that produces hydrogen from glucose, and emended description of the genus Anaerobaculum. Int. J. Syst. Evol. Microbiol. 62, 832-838. doi: 10.1099/ijs.0.024349-0

McKay, C. P., Stoker, C. R., Glass, B. J., Davé, A. I., Davila, A. F., Heldmann, J. L., et al. (2013). The icebreaker life mission to mars: a search for biomolecular evidence for life. Astrobiology 13, 334-353. doi: 10.1089/ast.2012.0878

McMurdie, P. J., and Holmes, S. (2013). phyloseq: an r package for reproducible interactive analysis and graphics of microbiome census data. PLoS One 8:e61217. doi: 10.1371/journal.pone.0061217

Menes, R. J., and Muxí, L. (2002). Anaerobaculum mobile sp. nov., a novel anaerobic, moderately thermophilic, peptide-fermenting bacterium that uses crotonate as an electron acceptor, and emended description of the genus Anaerobaculum. Int. J. Syst. Evol. Microbiol. 52, 157-164. doi: 10.1099/ 00207713-52-1-157

Miller, S. R., and Castenholz, R. W. (2000). Evolution of thermotolerance in hot spring cyanobacteria of the genus Synechococcus. Appl. Environ. Microbiol. 66, 4222-4229. doi: 10.1128/AEM.66.10.4222-4229.2000

Moreno-Paz, M., Gómez-Cifuentes, A., Ruiz-Bermejo, M., Hofstetter, O., Maquieira, Á, Manchado, J. M., et al. (2018). Detecting nonvolatile lifeand nonlife-derived organics in a carbonaceous chondrite analogue with a new multiplex immunoassay and its relevance for planetary exploration. Astrobiology 18, 1041-1056. doi: 10.1089/ast.2017.1747

Muñoz-Saez, C., Manga, M., and Hurwitz, S. (2018). Hydrothermal discharge from the El Tatio basin, Atacama, Chile. J. Volcanol. Geotherm. Res. 361, 25-35. doi: 10.1016/j.jvolgeores.2018.07.007

Nakagawa, T., and Fukui, M. (2003). Molecular characterization of community structures and sulfur metabolism within microbial streamers in Japanese hot springs. Appl. Environ. Micrbiol. 69, 7044-7057. doi: 10.1128/AEM.69.12.70447057.2003

Navarro-González, R., Rainey, F. A., Molina, P., Bagaley, D. R., Hollen, B. J., De La Rosa, J., et al. (2003). Mars-like soils in the atacama desert, chile, and the dry limit of microbial life. Science 302, 1018-1021. doi: 10.1126/science.1089143

Nepomnyashchaya, N. Y., Slobodkina, G. B., Baslerov, R. V., Chernyh, N. A., Bonch-Osmolovskaya, E. A., Netrusov, A. I., et al. (2012). Moorella humiferrea sp. nov., a thermophilic, anaerobic bacterium capable of growth via electron shuttling between humic acid and Fe(III). Int. J. Syst. Evol. Micr. 62, 613-617. doi: 10.1099/ijs.0.029009-0

Nicolau, C., Reich, M., and Lynne, B. (2014). Physico-chemical and environmental controls on siliceous sinter formation at the high-altitude El Tatio geothermal field, Chile. J. Volcanol. Geotherm. Res. 282, 60-76. doi: 10.1016/j.jvolgeores. 2014.06.012

Oksanen, J., Blanchet, F. G., Friendly, M., Kindt, R., Legendre, P., McGlinn, D., et al. (2017). Vegan: Community Ecology Package. R package version 2.4-3. Available at: https://CRAN.R-project.org/package=vegan.

Pagès, A., Grice, K., Welsh, D. T., Teasdale, P. T., Van Kranendonk, M. J., and Greenwood, P. (2015). Lipid biomarker and isotopic study of community distribution and biomarker preservation in a laminated microbial mat from shark bay, Western Australia. Microb. Ecol. 70, 459-472. doi: 10.1007/s00248015-0598-3

Pantcost, R. D., Pressley, S., Coleman, J. M., Benning, L. G., and Mountain, B. W. (2005). Lipid biomolecules in silica sinters: indicators of microbial diversity. Environ. Microbiol. 7, 66-77. doi: 10.1111/j.1462-2920.2004.00686.x

Paredes-Sabja, D., Setlow, P., and Sarker, M. R. (2011). Germination of spores of Bacillales and Clostridiales species: mechanisms and proteins involved. Trends Microbiol. 19, 85-94. doi: 10.1016/j.tim.2010.10.004

Parenteau, M. N., and Cady, S. L. (2010). Microbial biosignatures in ironmineralized phototrophic mats at chocolate pots hot springs, yellowstone national park, united states. Palaios 25, 97-111. doi: 10.2110/palo.2008.p08$133 \mathrm{r}$

Parro, V., Blanco, Y., Puente-Sánchez, F., Rivas, L. A., Moreno-Paz, M., Echeverria, A., et al. (2018). Biomarkers and metabolic patterns in the sediments of evolving glacial lakes as a proxy for planetary lake exploration. Astrobiology 18, 586-606. doi: 10.1089/ast.2015.1342

Parro, V., de Diego-Castilla, G., Moreno-Paz, M., Blanco, Y., Cruz-Gil, P., Rodríguez-Mandredi, J. A., et al. (2011a). A microbial oasis in the hypersaline atacama subsurface discovered by a life detector chip: implications for the search of life on mars. Astrobiology 11, 969-996. doi: 10.1089/ast.2011. 0654

Parro, V., de Diego-Castilla, G., Rodríguez-Manfredi, J. A., Rivas, L. A., BlancoLópez, Y., Sebastián, E., et al. (2011b). SOLID3: a multiplex antibody microarray-based optical sensor instrument for in situ life detection in planetary exploration. Astrobiology 11, 15-28. doi: 10.1089/ast.2010.0501

Parro, V., Fernández-Remolar, D., Rodríguez-Manfredi, J. A., Cruz-Gil, P., Rivas, L. A., Ruiz-Bermejo, M., et al. (2011c). Classification of modern and old Río Tinto sedimenary deposits through the biomolecular record using a life marker biochip: implications for detecting life on mars. Astrobiology 11, 29-43. doi: 10.1089 /ast.2010.0510

Parro, V., Fernández-Calvo, P., Rodríguez Manfredi, J. A., Moreno-Paz, M., Rivas, L. A., García-Villadangos, M., et al. (2008a). SOLID2: an antibody array-based lifedetector instrument in a mars drilling simulation experiment (MARTE). Astrobiology 8, 987-999. doi: 10.1089/ast.2007.0126

Parro, V., Rivas, L. A., and Gómez-Elvira, J. (2008b). Protein microarrays-based strategies for life detection in astrobiology. Space Sci. Rev. 135, 293-311. doi: 10.1007/s11214-007-9276-1

Pepe-Ranney, C., Berelson, W. M., Corsetti, F. A., Treant, M., and Spear, J. R. (2012). Cyanobacterial construction of hot spring siliceous stromatolites in yellowstone national park. Environ. Microbiol. 14, 1182-1197. doi: 10.1111/j. 1462-2920.2012.02698.x 
Phoenix, V. R., Bennett, P. C., Engel, A. S., Tyler, S. W., and Ferris, F. G. (2006). Chilean high-altitude hot-spring sinters: a model system for UV screening mechanisms bt early precambrian cyanobacteria. Geobiology 4, 15-28. doi: 10.1111/j.1472-4669.2006.00063.x

Poger, D., and Mark, A. E. (2015). A ring to rule them all: the effect of cyclopropane fatty acids on the fluidity of lipid biolayers. J. Phys. Chem. B 119, 5487-5495. doi: 10.1021/acs.jpcb.5b00958

Preu $\beta$, A., Schauder, R., and Fuchs, G. (1989). Carbon isotopic fractionation by autotrophic bacteria with three different $\mathrm{CO} 2$ fixation pathways. Z. Naturforsch. Teil. C 44, 397-402. doi: 10.1515/znc-1989-5-610

Purcell, D., Sompong, U., Yim, L. C., Barraclough, T. G., Peerapornpisal, Y., and Pointing, S. B. (2007). The effects of temperature, $\mathrm{pH}$ and sulphide on the community structure of hyperthermophilic streamers in hot springs of northern Thailand. FEMS Microbiol. Ecol. 60, 456-466. doi: 10.1111/j.1574-6941.2007. 00302.x

Quandt, L., Gottschalk, H., Ziegler, H., and Stichler, W. (1977). Isotope discrimination by photosyntetic bacteria. FEMS Microbiol. Lett. 1, 125-128. doi: 10.1111/j.1574-6968.1977.tb00596.x

Renaut, R. W., Jones, B., and Tiercelin, J. J. (1998). Rapid in situ silicification of microbes at loburu hot springs, lake bogoria, kenya rift valley. Sedimentology 45, 1083-1103. doi: 10.1046/j.1365-3091.1998.00194.x

Révész, K., Qi, H., and Coplen, T. B. (2012). "Determination of the $\delta 15 \mathrm{~N}$ and $\delta 13 \mathrm{C}$ of total nitrogen and carbon in solids. RSIL lab code 1832, chap. 5 of Stable isotope-ratio methods," in Methods of the Reston Stable Isotope Laboratory (slightly revised from version 1.1 released in 2007), eds C. Révész and T. B. Coplen (Reston: U.S. Geological Survey).

Reysenbach, A. L., Wickham, G. S., and Pace, N. R. (1994). Phylogenetic analysis of the hyperthermophilic pink filament community in octopus spring, yellowstone national park. Appl. Environ. Microbiol. 60, 2113-2119.

Rivas, L. A., Aguirre, J., Blanco, Y., González-Toril, E., and Parro, V. (2011). Graphbased deconvolution analysis of multiplex sandwich microarray immunoassays: applications for environmental monitoring. Environ. Microbiol. 13, 1421-1432. doi: 10.1111/j.1462-2920.2011.02442.x

Rivas, L. A., García-Villadangos, M., Moreno-Paz, M., Cruz-Gi, 1. P, GómezElvira, J., and Parro, V. (2008). A 200-antibody microarray biochip for environmental monitoring: searching for universal microbial biomarkers through immunoprofiling. Anal. Chem. 80, 7970-7979. doi: 10.1021/ac8008093

Rodgers, K. A., Browne, P. R. L., Buddle, T. F., Cook, K. L., Greatrex, R. A., Hampton, W. A., et al. (2004). Silica phases in sinters and residues from geothermal fields of New Zealand. Earth Sci. Rev. 66, 1-61. doi: 10.1016/j. earscirev.2003.10.001

Russell, M. J. (2018). Green rust: the simple organizing seed of all life. Life 8:35. doi: 10.3390/life8030035

Sánchez-García, L., Aeppli, C., Parro, V., Fernandez-Remolar, D., GarcíaVilladangos, M., Chong-Díaz, G., et al. (2018). Molecular biomarkers in the subsurface of the salar grande (Atacama, Chile) evaporitic deposits. Biogeochemistry 144, 31-52. doi: 10.1007/s10533-018-0477-3

Schloss, P. D., Westcott, S. L., Ryabin, T., Hall, J. R., Hartmann, M., Hollister, E. B., et al. (2009). Introducing mothur: open-source, platform-independent, community-supported software for describing and comparing microbial communities. Appl. Environ. Microbiol. 75, 7537-7541. doi: 10.1128/AEM. 01541-09

Schopf, J. W., and Packer, B. M. (1987). Early Archean (3.3-billion to 3.5billionyear- old) microfossils from Warrawoona Group, Australia. Science 237, 70-73. doi: 10.1126/science.11539686

Shiea, J., Brassell, S. C., and Ward, D. M. (1991). Comparative analysis of extractable lipids in hot spring microbial mats and their component photosynthetic bacteria. Org. Geochem. 17, 309-319. doi: 10.1016/01466380(91)90094-Z

Sillitoe, R. H. (2015). Epithermal paleosurfaces. Miner. Deposita 50, 767-793. doi: 10.1007/s00126-015-0614-z

Skirnisdottir, S., Hreggvidsson, G. O., Hjorleifsdottir, S., Marteinsson, V. T., Petursdottir, S. K., Holst, O., et al. (2000). Influence of sulfide and temperature on species composition and community structure of hot spring microbial mats. Appl. Environ. Microbiol. 66, 2835-2841. doi: 10.1128/AEM.66.7.2835-2841. 2000

Smith, B. Y., Turner, S. J., and Rodgers, K. A. (2003). Opal-A and associated microbes from wairakei, new zealand: the first 300 days. Mineral. Mag. 67, 563-579. doi: 10.1180/0026461036730118

Steinbüchel, A. (1991). "Polyhydroxyalkanoic acids," in Biomaterials: Novel Materials from Biological Sources, ed. D. Byrom (Berlin: Springer), 124-213.

ten Haven, H. L., de Leeuw, J. W., Sinninghe Damste, J. S., Schenck, P. A., Palmer, S. E., and Zumberge, J. E. (1988). "Application of biological markers in the recognition of palaeo-hypersaline environments," in Lacustrine Petroleum Source Rocks, Vol. 40, eds K. Kelts, A. Fleet, and M. Talbot (London: Blackwell), $123-130$.

Tobler, D. J., and Benning, L. G. (2011). Bacterial diversity in five Icelandic geothermal waters: temperature and sinter growth rate effects. Extremophiles 15, 473-485. doi: 10.1007/s00792-011-0378-z

Trumpolt, C. W., Crain, M., Cullison, G. D., Flanagan, S. J. P., Siegel, L., and Lathrop, S. (2005). Perchlorate: sources, uses, and occurrences in the environment. Rem. J. 16, 65-89. doi: 10.1002/rem.20071

van der Meer, M. T., Schouten, S., de Leeuw, J. W., and Ward, D. M. (2000). Autotrophy of green non-sulphur bacteria in hot spring microbial mats: biological explanations for isotopically heavy organic carbon in the geological record. Environ. Microbiol. 2, 428-435. doi: 10.1046/j.1462-2920.2000.00 124.x

Van Kranendonk, M. J., Deamer, D. W., and Djokic, T. (2017). Life springs. Sci. Am. 317, 28-35. doi: 10.1038/scientificamerican0817-28

Walter, M. R. (1976). Stromatolites, Vol. 20. Amsterdam: Elsevier Science Ltd.

Walter, M. R., and Des Marais, D. J. (1993). Preservation of biological information in thermal-spring deposits - developing a strategy for the search for fossil life on mars. Icarus 101, 129-143. doi: 10.1006/icar.1993.1011

Ward, D. M., Ferris, M. J., Nold, S. C., and Bateson, M. M. (1998). A natural view of microbial biodiversity within hot spring cyanobacterial mat communities. Microbiol. Mol. Biol. Rev. 62, 1353-1370.

Warren-Rhodes, K. A., Lee, K., Archer, S. D. J., Lacap-Bugler, D. C., Ng-Boyle, L., Wettergreen, D., et al. (2018). Soil microbial habitats in an extreme desert mars-analogue environment. bioRxiv [Preprint] doi: 10.1101/269605

Westall, F., Campbell, K. A., Bréhéret, J.-G., Foucher, F., Gautret, P., Hubert, A., et al. (2015). Archean (3.33 Ga) microbe-sediment systems were diverse and flourished in a hydrothermal context. Geology 43, 615-618. doi: 10.1130/ G36646.1

Wilhelm, M. B., Davila, A. F., Parenteau, M. N., Jahnke, L. L., Abate, M., Cooper, G., et al. (2018). Constraints on the metabolic activity of microorganisms in atacama surface soils inferred from refractory biomarkers: implications for martian habitability and biomarker detection. Astrobiol 18, 955-966. doi: 10. 1089/ast.2017.1705

Zhang, C. L., Huang, Z., Li, Y.-L., Romanek, C. S., and Mills, G. L. (2007). Lipid biomarkers, carbon isotopes, and phylogenetic characterization of bacteria in california and nevada hot springs. Geomicrobiol. J. 24, 519-534. doi: 10.1080/ 01490450701572515

Conflict of Interest Statement: The authors declare that the research was conducted in the absence of any commercial or financial relationships that could be construed as a potential conflict of interest.

Copyright (C) 2019 Sanchez-Garcia, Fernandez-Martinez, García-Villadangos, Blanco, Cady, Hinman, Bowden, Pointing, Lee, Warren-Rhodes, Lacap-Bugler, Cabrol, Parro and Carrizo. This is an open-access article distributed under the terms of the Creative Commons Attribution License (CC BY). The use, distribution or reproduction in other forums is permitted, provided the original author(s) and the copyright owner(s) are credited and that the original publication in this journal is cited, in accordance with accepted academic practice. No use, distribution or reproduction is permitted which does not comply with these terms. 